\title{
Chemical studies of the passivation of GaAs surface recombination using sulfides and thiols
}

\author{
Sharon R. Lunt, Gail N. Ryba, Patrick G. Santangelo, and Nathan S. Lewis ${ }^{\text {a) }}$ \\ Division of Chemistry and Chemical Engineering, California Institute of Technology, \\ Pasadena, California 91125
}

(Received 3 April 1991; accepted for publication 3 September 1991)

\begin{abstract}
Steady-state photoluminescence, time-resolved photoluminescence, and x-ray photoelectron spectroscopy have been used to study the electrical and chemical properties of GaAs surfaces exposed to inorganic and organic sulfur donors. Despite a wide variation in $\mathrm{S}^{2-}$ (aq) concentration, variation of the $p \mathrm{H}$ of aqueous $\mathrm{HS}^{-}$solutions had a small effect on the steady-state $n$-type GaAs photoluminescence intensity, with surfaces exposed to $p \mathrm{H}=8,0.1$ $\mathrm{M} \mathrm{HS}^{-}$(aq) solutions displaying comparable luminescence intensity relative to those treated with $p \mathrm{H}=14,1.0-\mathrm{M} \mathrm{Na} 2 \mathrm{~S} \cdot 9 \mathrm{H}_{2} \mathrm{O}$ (aq). Organic thiols (R-SH, where $R=-\mathrm{CH}_{2} \mathrm{CH}_{2} \mathrm{SH}$ or $-\mathrm{C}_{6} \mathrm{H}_{4} \mathrm{Cl}$ ) dissolved in nonaqueous solvents were found to effect increases in steady-state luminescence yields and in time-resolved luminescence decay lifetimes of (100)-oriented GaAs. X-ray photoelectron spectroscopy showed that exposure of GaAs surfaces to these organic systems yielded thiols bound to the GaAs surface, but such exposure did not remove excess elemental As and did not form a detectable $\mathrm{As}_{2} \mathrm{~S}_{3}$ overlayer on the GaAs. These results imply that complete removal of $\mathrm{As}^{0}$ or formation of monolayers of $\mathrm{As}_{2} \mathrm{~S}_{3}$ is not necessary to cffect a reduction in the rccombination ratc at etched GaAs surfaces. Other compounds that do not contain sulfur but that are strong Lewis bases, such as methoxide ion, also improved the GaAs steady-state photoluminescence intensity. These results demonstrate that a general class of electrondonating reagents can be used to reduce nonradiative recombination at GaAs surfaces, and also imply that prior models focusing on the formation of monolayer coverages of $\mathrm{As}_{2} \mathrm{~S}_{3}$ and $\mathrm{Ga}_{2} \mathrm{~S}_{3}$ are not adequate to describe the passivating behavior of this class of reagents. The timeresolved, high level injection experiments clearly demonstrate that a shift in the equilibrium surface Fermi-level energy is not sufficient to explain the luminescence intensity changes, and confirm that $\mathrm{HS}^{-}$and thiol-based reagents induce substantial reductions in the surface recombination velocity through a change in the GaAs surface state recombination rate.
\end{abstract}

\section{INTRODUCTION}

The use of $\mathrm{Na}_{2} \mathrm{~S} \cdot 9 \mathrm{H}_{2} \mathrm{O}$ has been reported recently by Yablonovitch, Sandroff, and co-workers to decrease surface recombination rates at $\mathrm{GaAs} / \mathrm{air}$ interfaces and to improve the electrical characteristics of GaAs bipolar transistors. ${ }^{1}$ This system is notable because the surface recombination velocity under high level injection of $\mathrm{Na}_{2} \mathrm{~S}$-treated (100) GaAs surfaces is $10^{3} \mathrm{~cm} \mathrm{~s}^{-1}$ as opposed to the $10^{6}-10^{7} \mathrm{~cm} \mathrm{~s}^{-1}$ value that is characteristic of unpassivated GaAs/air interfaces. ${ }^{1(\mathbf{a}), 2}$ Apart from the observation that reductions in surface recombination velocity $(S)$ can be obtained with $\mathrm{Na}_{2} \mathrm{~S},\left(\mathrm{NH}_{4}\right)_{2} \mathrm{~S}$, and other salts that yield aqueous sulfur species, ${ }^{1,3-5}$ little is known about the chemical reactivity of the GaAs surface sites. To address this issue, we report the surface electrical and chemical properties of (100)-oriented GaAs that has been exposed to a variety of sulfur, nitrogen, and oxygen donors. Many of these treatments yielded improved GaAs surface recombination properties, demonstrating that a general class of chemical reactivity can be exploited to obtain information on the GaAs surface state properties.

Additionally, although numerous spectroscopic and

author to whom correspondence should be addressed. electrical studies of $\mathrm{Na}_{2} \mathrm{~S}$-coated GaAs surfaces have been performed, ${ }^{3,4,6-14}$ there is still controversy over the mechanism of surface passivation in the GaAs- $\mathrm{Na}_{2} \mathrm{~S} \cdot 9 \mathrm{H}_{2} \mathrm{O}$ system. Some workers have associated the improvements in surface recombination rates with the bonding and/or etching of electrical traps by the basic aqueous sulfide solutions. ${ }^{1}$ Other investigators have suggested that the traps might be associated with excess elemental As, which is presumably etched away by the $\mathrm{Na}_{2} \mathrm{~S}$ solution. ${ }^{1,5,15} \mathrm{An}$ other theory is that a slight shift in the surface Fermi level pinning position towards the GaAs valence band edge is responsible for the improved photoluminescence signals, and that passivation effects due to a decrease in the surface trap density and/or cross section are a secondary effect. ${ }^{8,15}$ Support for this latter hypothesis has been obtained from deep-level transient spectroscopy, ${ }^{8(b)}$ from valence band shifts in vacuum photoemission experiments, ${ }^{7}$ and from field effect measurements of the equilibrium band bending at $\mathrm{Na}_{2} \mathrm{~S}$-treated GaAs surfaces. ${ }^{8(a)}$ However, measurements of the surface Fermi-level position under dark equilibrium conditions are nol sufficient to define the surface carrier concentrations under strong illumination, ${ }^{14,16}$ so other data must also be obtained to understand the electrical effects of the GaAs surface modifications.

In this work, we have used steady-state, low level in- 
jection, photoluminescence (PL) methods and time-resolved, high level injection, photoluminescence methods ${ }^{17}$ to probe the electrical recombination properties of various GaAs surfaces. Radiative lifetime data obtained under high level injection conditions are relatively insensitive to the position of the dark, equilibrium surface Fermi level, ${ }^{16,18}$ therefore chemically induced changes in surface recombination rates can be probed unambiguously in such experiments. In addition, we have used high-energy resolution $\mathrm{x}$-ray photoelectron spectroscopy ${ }^{19}$ to investigate the elemental As stoichiometry and to study the formation of arsenic sulfides after the GaAs surface has been exposed to the desired chemical reagent. These studies have been performed in a rigorously anaerobic environment, so that the effects of native oxide growth on the formation of $\mathrm{As}_{2} \mathrm{~S}_{3}$ and $\mathrm{Ga}_{2} \mathrm{~S}_{3}$ precipitates [from a chemical reaction with the $\mathrm{Na}_{2} \mathrm{~S}(\mathrm{aq})$ solutions] can be minimized and investigated systematically. We have also exposed the GaAs surface to a variety of etches in order to obtain either a stoichiometric surface, an $\mathbf{A s}^{0}$-rich surface, or an oxidized surface. These experiments have enabled us to probe correlations between the initial surface chemical composition and the stoichiometry of the modified GaAs interface.

\section{EXPERIMENTAL}

\section{A. Samples and chemicals}

All experiments in this work were performed with $n$ type (100)-oriented $\mathrm{GaAs}$, which varied in dopant density from $10^{14}$ to $10^{18} \mathrm{~cm}^{-3}$. Most bulk GaAs samples used in $\mathrm{x}$-ray photoelectron spectroscopy (XPS) experiments were performed on (100)-oriented GaAs single crystals with donor densities $\left(N_{d}\right)$ of $10^{17} \mathrm{~cm}^{-3}$ (Morgan Semiconductor, Inc. or Wacker Inc.) or on low doped, nominally intrinsic, GaAs samples. Some steady state PL measurements were also performed on the $N_{d}=10^{17} \mathrm{~cm}^{-3}$ bulk GaAs samples; however, in order to maximize the surface sensitivity of the photoluminescence signals, the majority of the steady state experiments were performed with thin, lightly doped, GaAs epilayer structures. Except where otherwise noted, these samples consisted of a semi-insulating GaAs substrate, followed by a layer of $\mathrm{Al}_{0.4} \mathrm{Ga}_{0.6} \mathrm{As}$ (1000 $\AA$ thick), a layer of GaAs (1.01 $\mu \mathrm{m}$ thick) doped at $10^{15}$ $\mathrm{cm}^{-3}$ ( $n$-type), and then another layer of $\mathrm{Al}_{0.4} \mathrm{Ga}_{0.6} \mathrm{As}$ (1000 $\AA$ thick $){ }^{20}$ For convenience, these samples will be designated as the $1.0-\mu \mathrm{m}$ epilayer GaAs samples. For experiments that probed the effects of treatments on the GaAs surface, the top $\mathrm{Al}_{0.4} \mathrm{Ga}_{0.6}$ As cap layer was removed by etching the sample for $4 \mathrm{~min}$ in a solution of $0.05 \% \mathrm{Br}_{2}$ (by vol.) in methanol. The PL intensity was monitored during the etching process, and the etch was stopped when no further decrease in the PL signal was observed in response to a $15 \mathrm{~s}$ immersion into the $\mathrm{Br}_{2} /$ methanol solution.

In order to confine carriers to a narrow region and thereby maintain high injection during the course of the photoluminescence measurements, time-resolved photoluminescence experiments were conducted on samples with a layered structure that consisted of a semi-insulating $\mathrm{GaAs}$ substrate, followed by a layer of $\mathrm{Al}_{0.3} \mathrm{Ga}_{0.7} \mathrm{As}$ (1000 thick) a layer of GaAs ( $2.8 \mu \mathrm{m}$ thick), and then a layer $\mathrm{Al}_{0.3} \mathrm{Ga}_{0.7} \mathrm{As}$ ( $1000 \AA$ thick). ${ }^{21^{\circ}}$ These samples will be designated as the 2.8- $\mu \mathrm{m}$-thick epilayer GaAs samples. When desired, the $\mathrm{Al}_{0.3} \mathrm{Ga}_{0.7} \mathrm{As}$ cap was removed by etching the sample for $4 \mathrm{~min}$ in 1:8:500 (volume ratio) of a $\mathrm{H}_{2} \mathrm{SO}_{4}$ (con.): $30 \% \mathrm{H}_{2} \mathrm{O}_{2}(\mathrm{aq}): \mathrm{H}_{2} \mathrm{O}$ solution. The exposed GaAs layer was then etched and manipulated as described below for the bulk GaAs samples.

Three types of etches were uscd in this work..$^{22}$ In the first procedure, samples were etched sequentially in $0.05 \%$ $\mathrm{Br}_{2}-\mathrm{CH}_{3} \mathrm{OH}$ and $1.0-\mathrm{M} \mathrm{KOH}(\mathrm{aq})$ solutions, with each etch being $15 \mathrm{~s}$ in duration. After the $\mathrm{KOH}$ etch, the sample was rinsed with deionized water and then dried under a stream of $\mathrm{N}_{2}(\mathrm{~g})$. Before further use of the GaAs, this etching procedure was performed three times on each sample. This etch leaves a surface with minimal oxides and elemental As, and will be referred to as etch A (or the "near-stoichiometric" etch). ${ }^{23}$. This etch was the one most commonly used to give a good starting GaAs surface, and was used as the initial treatment except when otherwise noted.

In some experiments, GaAs samples were subsequently etched in 1:1:100 (con. $\mathrm{H}_{2} \mathrm{SO}_{4}: 30 \% \mathrm{H}_{2} \mathrm{O}_{2}: \mathrm{H}_{2} \mathrm{O}$ ) solutions for $30 \mathrm{~s}$, and were then rinsed with deionized water and dried under a stream of $\mathrm{N}_{2}(\mathrm{~g})$. This procedure resulted in a nonstoichiometric surface with an excess of elemental As on the GaAs surface, ${ }^{22-24}$ and will be referred to as etch B (or the $\mathrm{As}^{0}$-rich etch). Etch $\mathrm{C}$ consisted of exposure of the GaAs surface to etch A followed by exposure to $30 \% \mathrm{H}_{2} \mathrm{O}_{2}$ for $30 \mathrm{~s}$, and resulted in the formation of an oxidized GaAs surface layer. ${ }^{22,23}$

The organic reagents were used as received ( $99 \%$ or better purity) from Aldrich Chemical Co. The organic reagents were dissolved in diethylether or in carbon tetrachloride to make solutions of $1.0 \mathrm{M}$, unless otherwise noted. The sodium salts of several of the organic reagents were formed by addition of a 5\% molar excess of sodium to a 1.0-M solution of the organic reagent in diethylether. $\mathrm{Na}_{2} \mathrm{~S} \cdot 9 \mathrm{H}_{2} \mathrm{O}(\mathrm{s})$ was obtained from Mallinckrodt in $98.38 \%$ purity, and NaHS(s) was obtained in $99 \%$ purity from Aldrich.The $p \mathrm{H}$ of the aqueous $\mathrm{Na}_{2} \mathrm{~S}$ and NaHS solutions was adjusted by addition of $12-\mathrm{M} \mathrm{HCl}(\mathrm{aq})$ or $1.0 \mathrm{M}$ $\mathrm{NaOH}$, as necessary.

Chemical treatments of the GaAs samples were performed by immcrsing the etched GaAs surface into a Pyrex beaker containing a solution of the desired reagent (1.0-M concentration, unless otherwise specified) for time periods of 1-60 min, with an immersion time of $30 \mathrm{~min}$ used for most experiments. Except where otherwise noted, all solutions were open to the ambient air while in contact with the GaAs samples. The samples were then removed from the beaker, allowed to dry under $\mathrm{N}_{2}(\mathrm{~g})$, and then transferred either to the XPS instrument or to the PL apparatus.

\section{B. Steady-state photoluminescence experiments}

Steady-state photoluminescence (PL) data were obtained using either an Ar-ion laser at $514 \mathrm{~nm}(100 \mathrm{~mW})$ or a $\mathrm{He}-\mathrm{Ne}$ laser at $632.8 \mathrm{~nm}(10 \mathrm{~mW})$. Both lasers werc focused to produce illuminated sample areas $\approx 1 \mathrm{~mm}$ in 
diameter. In preliminary experiments, the relative trends in PL intensity for surface treatments with aqueous sodium sulfide on either $2.8-\mu \mathrm{m}$ GaAs epilayer samples or on $10^{17}$-doped bulk GaAs samples were found to be independent of the choice of excitation wavelength ( $514 \mathrm{~nm}$ vs 633 $\mathrm{nm}$ ), so $633 \mathrm{~nm}$ excitation was used for the majority of the experiments described below.

For either excitation wavelength, the PL signal from the GaAs was directed through a monochromator (SPEX $1681 \mathrm{~B}, 1.25-\mathrm{mm}$ slits) that was equipped with a long pass filter (transmitting $\lambda>740 \mathrm{~nm}$ ). Light detection was performed with a conventional photomultiplier tube (Hamamatsu R632-01). A scan of the PL intensity was recorded between 800 and $900 \mathrm{~nm}$ at a scan rate of $1 \mathrm{~nm} / \mathrm{s}$; the maximum PL signal was then recorded as the characteristic value for this sample. The wavelength of the peak maximum $(874 \mathrm{~nm})$ did not shift noticeably after any of the surface treatments.

In order to minimize oxidation of the GaAs, ${ }^{25}$ all PL measurements were performed with the sample placed in a two-necked glass cell equipped with a stopcock. The cell was continuously purged with $\mathrm{N}_{2}(\mathrm{~g})$. The samples were etched (in ambient air) as described above, placed in the cell, and a baseline PL measurement was obtained. The samples were then transferred in air to the appropriate solution, treated with the desired chemical reagent, reinserted into the $\mathrm{N}_{2}$-purged cell, and the PL peak was then rescanned. Frequently, there was some increase in the PL intensity over a period of about $10 \mathrm{~min}$, after which the PL signal level remained constant. The data were recorded after the peak had reached a constant intensity. This process was found to yield consistent trends in PL intensity for the various reagents studied in this work. The increase in PL with time was clearly due to a photochemical step, ${ }^{5}$ because after the PL signal had reached a maximum value on a sample of GaAs, illumination of a different portion of the same GaAs surface resulted in an initially low PL intensity and also produced a similar time-dependence of the PL signal. After re-etching treated $\mathrm{GaAs}$ surfaces with the repetitive $\mathrm{Br}_{2}-\mathrm{CH}_{3} \mathrm{OH}$ and $1.0-\mathrm{M} \mathrm{KOH}(\mathrm{aq})$ procedure (etch $\mathrm{A}$ ), the PL intensity always returned to the baseline value. For all samples, exposure of the $\mathrm{Na}_{2} \mathrm{~S}$ films to air for more than a few minutes usually resulted in adsorption of water from the air; this process was readily identified because the water wetted the film and eventually reduced the PL intensity back to the baseline value of etched samples. Such long-term exposure to air was therefore avoided in the measurements reported herein.

Some experiments were performed to investigate the effects of spin-coating ${ }^{1}$ versus the immersion and drying procedures described above. Using a bulk $\mathrm{GaAs}$ specimen $\left(N_{d}=10^{17} \mathrm{~cm}^{-3}\right.$, etched with etch A) in contact with 1.0-M Na $25 \cdot 9 \mathrm{H}_{2} \mathrm{O}$ (aq) solutions, essentially identical PL signals were obtained from the spin coating method versus the immersion and drying procedure. Most of our work was therefore performed using the more straightforward immersion/drying procedure, as described above.

Some experiments were also performed using solutions specifically prepared to minimize the amount of oxidized sulfur and to maximize the amount of sulfur in the -2 oxidation state. In these experiments, NaHS $\left(\mathrm{H}_{2} \mathrm{O}\right)_{x}$ was dissolved in deaerated water to produce a 1.0-M NaHS solution; $0.1-\mathrm{M} \mathrm{NaN}{ }_{3}$ was then added to this solution to reduce any residual polysulfide species. The $p \mathrm{H}$ was then adjusted by addition of either $\mathrm{HCl}$ or $\mathrm{NaOH}$, as required. Re-oxidation of the $\mathrm{HS}^{-}$was prevented by maintaining a stream of $\mathrm{N}_{2}(\mathrm{~g})$ through the solution during the reduction with $\mathrm{NaN}_{3}$ and through all subsequent manipulation steps. This procedure was found to minimize the oxidized sulfur content relative to that obtained from solutions made with commercial $\mathrm{Na}_{2} \mathrm{~S} \cdot 9 \mathrm{H}_{2} \mathrm{O}(\mathrm{s})$ and no reductant present.

\section{Time-resolved photoluminescence studies}

Time-resolved photoluminescence experiments were performed using time-correlated single photon counting instrumentation. The excitation source was a Coherent Model 701-2 dye laser that was pumped by the modelocked, second harmonic output of a Nd:YAG laser (Coherent Inc. "Antares" Laser System). The dye laser pulses were less than $10 \mathrm{ps}$ in duration, the repetition rate was 152 $\mathrm{kHz}$, and the power per pulse was $4.6 \mathrm{~nJ}$ at $620 \mathrm{~nm}$ or 13.1 $\mathrm{nJ}$ at $685 \mathrm{~nm}$. All time-resolved PL studies were carried out under high injection conditions. The beam was focused to a spot with a diameter of $<100 \mu \mathrm{m}$ on the plane of the sample, yielding an incident flux of $10^{14}$ photons $\mathrm{cm}^{-2}$ pulse $^{-1}$. The absorption coefficient for GaAs at $656 \mathrm{~nm}$ $(1.89 \mathrm{eV})$ is $3.44 \times 10^{4} \mathrm{~cm}^{-1} ;{ }^{26}$ thus, after accounting for a $30 \%$ loss in power due to reflection at the GaAs/gas interface, this incident power resulted in an initial injection level in the first $0.10 \mu \mathrm{m}$ of approximately $10^{19} \mathrm{~cm}^{-3}$, and produced injection levels of $10^{18}$ carriers $\mathrm{cm}^{-3}$ after carrier diffusion through the 2.8- $\mu$ m-thick epilayer GaAs sample. All time-resolved PL experiments were performed on the sample with the $2.8-\mu \mathrm{m}$ GaAs epilayer structure.

The time-correlated photon counting apparatus consisted of an EG\&G Ortec Model 934 Quad Constant Fraction Discriminator, a Tennelec TC 864 Time-Amplitude Converter/Biased Amplifier and an EG\&G Ortec Spectrum Ace-4K Multichannel Analyzer. Trigger pulses were generated by an FND-100 photodiode, and were amplified and inverted by a Hewlett Packard $8447 \mathrm{~F}$ preamplifier. The room-temperature $\mathrm{GaAs}$ band-gap luminescence at $880 \mathrm{~nm}$ was detected using an accelerated Hamamatsu R928 Photomultiplier. ${ }^{27,28}$ Stray light was rejected using Hoya long pass cutoff filters at $740 \mathrm{~nm}$ that were placed in front of the Spex monochromator, and the monochromator was set to $880 \mathrm{~nm}$ with $1.25-\mathrm{mm}$ slits. The system response was determined by scattering the incident beam off of a strip of Teflon tape, with some scattered light directed into the photomultiplier tube. This procedure yielded a value of $\approx 350 \mathrm{ps}$ for the full-width at half-maximum of the system response; the full system response function was recorded and used in the convolution procedure described below.

Analysis of the time-resolved PL data was performed using a digital simulation program. ${ }^{17,18}$ In our simulation, photogenerated carriers were created in a delta time pulse with the appropriate penetration depth into the sample, and were then allowed to diffuse, to recombine radiatively 
and nonradiatively in the bulk, and to recombine nonradiatively at the front and back GaAs surfaces. The high injection levels of the experiment greatly simplified the simulation procedure, because the flat-band conditions established in the experiments justified neglect of drift terms in the simulation. Standard Shockley-Read-Hall trapping statistics were used to model the nonradiative processes, ${ }^{16}$ and the known radiative recombination coefficient of $2 \times 10^{-10} \mathrm{~cm}^{3} \mathrm{~s}^{-1}$ was used for the GaAs luminescence rate constant. ${ }^{29}$

For the samples of interest, the low-level injection bulk minority-carrier lifetime was sufficiently long that bulk nonradiative recombination processes were not important in determining the time decay of the PL signal; thus, the major factors that determined PL decays were carrier lumincscence, diffusion, and surface recombination. Because the carrier mobilities, sample thickness, injection levels, and GaAs radiative rate constants were known independently, the only adjustable parameter in the simulation was the surface trapping rate, which was varied from $10^{1}-10^{7}$ $\mathrm{cm} \mathrm{s}^{-1}$ in the simulations. The simulated PL response was then convoluted with the laser/photomultiplier tube/ electronics system response function, and the resulting time-dependent PL function was then compared directly with the experimental PL data. Simulations of PL data on the $\mathrm{Al}_{0.3} \mathrm{Ga}_{0.7} \mathrm{As}$ capped, $2.8-\mu \mathrm{m}$-thick $\mathrm{GaAs}$ samples yielded a value for $S$ of $500 \mathrm{~cm} \mathrm{~s}^{-1}$, which is in good agreement with literature values for this interface. ${ }^{29(a)} \mathrm{PL}$ decays for the other surface treatments were more rapid than that obtained with the $\mathrm{Al}_{0.3} \mathrm{Ga}_{0.7} \mathrm{As}$ cap layer, and $\mathrm{S}$ was found to range from $10^{4}$ to $10^{6} \mathrm{~cm} \mathrm{~s}^{-1}$ for these systems.

\section{X-ray photoelectron spectroscopy}

X-ray photoelectron spectroscopic (XPS) studies were performed using a high-energy resolution Surface Science Instruments Model 100 top hat monochromator (Al x rays, $1486.6 \mathrm{eV}$ ) or using a VG Mark II ESCAlab nonmonochromatic $\mathrm{x}$-ray source ( $\mathrm{Mg} \times$ rays, $1254 \mathrm{eV}$ ). The FWHM of the Au $4 f_{5 / 2}$ line was $0.95 \mathrm{eV}$ on the SSI instrument and was $1.61 \mathrm{eV}$ on the VG instrument. The base pressure was at least $1 \times 10^{-9}$ Torr in both instruments. The monochromatic $x$ rays from the SSI machine were used to obtain chemical information in the As $3 d$ and $2 p$ regions, while the use of the $\mathrm{Mg}$ source from the VG instrument eliminated interference from the As Auger lines ( $\approx 232 \mathrm{BeV}$ in $\mathrm{Al}$ XPS) and allowed the observation of signals in the $\mathrm{S} 2 s 229 \mathrm{BeV}$ region. All peaks are reported with respect to $\mathrm{C} 1 s=285.0 \mathrm{eV}$, but the actual measured value of the carbon peak for each spectrum is also reported in the tables. XPS data were analyzed using standard peak fitting routines to obtain peak areas. For analysis of the As $3 d$ regions, two sets of doublets, each constrained to a ratio of $1.5: 1$ and to a separation of $0.7 \mathrm{eV}$, were used to obtain fits for substrate As and elemental As. The separation between the substrate and elemental As doublets was constrained to $0.7-0.8 \mathrm{eV} .{ }^{24}$ The amorphous As-S component was fit with a broad singlet without any constraints.
The etching procedure for samples studied by XPS was the same as for steady-state PL measurements. However, to avoid interference from surface oxides, the etching solutions and all chemical reagent solutions were deaerated, and etching was performed in either a glove bag or in an $\mathrm{N}_{2}$-purged glove box. Except where otherwise noted, after immersion into aqueous solutions, the GaAs samples were rinsed thoroughly with deaerated $\mathrm{H}_{2} \mathrm{O}$; after immersion into organic solvents, the samples were rinsed with methanol. Dried and treated samples were transported to the XPS instrument, or between the two XPS machines, in glass vials that were sealed under $\mathrm{N}_{2}$ or Ar. The vials were opened in a glove box that was attached to the desired XPS instrument, and the GaAs samples were then introduced into the vacuum chamber of the instrument without deliberate exposure to oxygen.

Spin profiling experiments were performed using the following procedure. Bulk low doped GaAs samples were exposed to etch $B$ in a dry box containing flowing $\mathrm{N}_{2}(\mathrm{~g})$. These samples were analyzed by XPS, and were then returned to the dry box for subsequent exposure to 1.0-M $\mathrm{Na}_{2} \mathrm{~S} \cdot 9 \mathrm{H}_{2} \mathrm{O}(\mathrm{aq})$. After a 10-min exposure, the GaAs samples were spun dried and transferred back into the high vacuum chamber and another set of XPS data (which showed only sodium, oxygen, carbon, and sulfur) was taken. The sample was then removed, rotated on a spin coater, exposed to one drop of water, and spun to dryness. The XPS spectrum was then reexamined, and the spin/ etch/dry process was repeated until no further changes in the XPS spectrum were noted. This procedure is very similar to that described earlier for profiling oxide films on $\mathrm{Si}$ and GaAs. ${ }^{19,30}$

Overlayer coverages were calculated from the XPS signal intensities assuming uniform layers and using the equation:

$$
d_{a}=\lambda_{a} \cos \theta \cdot \ln \left[\left(I_{a} \sigma_{b} n_{b} \lambda_{b}\right) /\left(I_{b} \sigma_{a} n_{a} \lambda_{a}\right)+1\right],
$$

where $d$ is the thickness in angstroms, $\lambda_{x}$ is the escape depth of the species of interest, $n_{x}$ is the number density, $I_{x}$ is the peak area, $\theta$ is the angle between the surface normal and the detector, $\sigma_{x}$ is the Scofield cross section, the layer designated as " $a$ " is on top of the layer designated as " $b$," and the transmission functions are assumed to be equal for both phases. ${ }^{31}$ Escape depths were calculated using the method of Seah and Dench. ${ }^{32}$ The coverages in $\mathrm{mol} / \mathrm{cm}^{2}$ were then calculated by multiplying the calculated depth by the density of the species of interest.

\section{RESULTS}

\section{A. Steady-state photoluminescence}

\section{Aqueous sulfide solutions}

The effects of various surface treatments on surface recombination rates were investigated through room-temperature photoluminescence..(PL) measurements on (100)-oriented $n$-type GaAs samples. As expected, the absolute magnitude of the PL intensity was a function of the thickness and minority-carrier lifetime of the sample, ${ }^{16,33}$ 


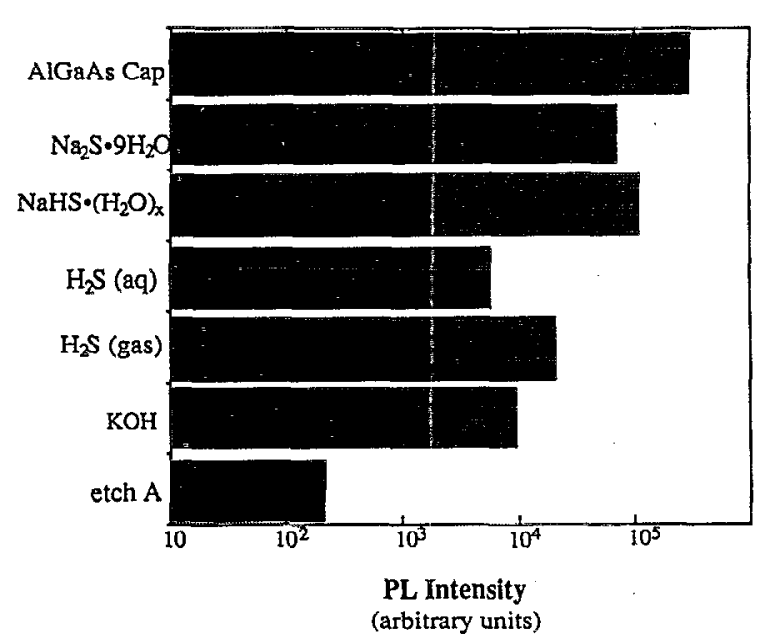

FIG. 1. Bar graph of steady-state photoluminescence intensity at $874 \mathrm{~nm}$ for $1.0 \mu \mathrm{m}$-thick epilayer (100) $n$-GaAs samples after exposure to various aqueous solutions. The excitation source was a He-Ne laser at $632.8 \mathrm{~nm}$. The concentration of all species was $1.0 \mathrm{M}$ with the exception of aqueous $\mathrm{H}_{2} \mathrm{~S}$, which was $0.1 \mathrm{M}$ in total sulfide $(p \mathrm{H}=1.5)$. The $\mathrm{H}_{2} \mathrm{~S}$ gas pressure was $\sim 1 \mathrm{~atm}$, and no $\mathrm{H}_{2} \mathrm{O}$ was deliberately introduced into this environment. Only the final PL signal for $\mathrm{H}_{2} \mathrm{~S}(\mathrm{~g})$ exposure is shown; the initial signal was approximately at the etch $\mathrm{A}$ level.

with thin, epitaxially grown, GaAs layers of low dopant density, high bulk lifetime, and a passivated back surface (at the $\mathrm{GaAs} / \mathrm{Al}_{x} \mathrm{Ga}_{1-x} \mathrm{As}$ contact) showing the greatest relative increase in PL intensity. Although some previous PL work has been performed using highly doped bulk GaAs samples, ${ }^{4,5,8(a)}$ the rather low dynamic range of the PL signal for our highly doped samples precluded accurate separation of the various chemical effects of interest in this work. Therefore, epilayer samples with a thin active region and a long minority-carrier lifetime (specifically, the 1.0$\mu \mathrm{m}$ epilayer GaAs samples) were used to obtain most of the quantitative PL intensity data for the surface treatments reported in this work.

a. $p H$ dependence of the steady-state photoluminescence intensity: $H S^{-}$vs $S^{2-}$ ions. Figure 1, Table I, and Table II report the steady-state, low level injection, GaAs PL data for various surface treatments. All steady-state PL data in Tables I and II are reported as the ratio of the PL signal for the surface of interest relative to that observed for an etched (etch $\mathrm{A}$ ) GaAs surface under the same experimental conditions. Under these conditions, a 300 fold increase in PL intensity was obtained after immersion of the 1.0$\mu \mathrm{m}$-thick epilayer GaAs sample into an unbuffered $(\mathrm{pH}$ $\approx 14$ ) $1.0-\mathrm{M} \mathrm{Na} \mathrm{N}_{2} \mathrm{~S} \cdot 9 \mathrm{H}_{2} \mathrm{O}(\mathrm{aq})$ solution (Table I, Sec. A, and Fig. 1). This PL increase is very similar to that reported by Sandroff et al., and indicates that our surface passivation procedures and GaAs sample properties were similar to those used in the previous work on this system. ${ }^{1}$ Notably, as reported in Fig. 1 and Table I, Scc. A, a slight increase in PL intensity was observed when the GaAs sample was exposed to $1.0-\mathrm{M} \mathrm{NaHS} \cdot\left(\mathrm{H}_{2} \mathrm{O}\right)_{x}(p \mathrm{H} \approx 12)$. Similar PL intensities were observed even when the $p \mathrm{H}$ was lowered to $<8$ (Table I, Sec. A). Since $\mathrm{H}_{2} \mathrm{~S}$ has $p K \alpha$ val-
TABLE I. PL intensity (arbitrary units) at $874 \mathrm{~nm}$ for $1.0-\mu \mathrm{m}$-thick epilayer (100) $n$-GaAs. Excitation source was a He-Ne laser at $632.8 \mathrm{~nm}$. Time of treatment was $30 \mathrm{~min}$ and the nonaqueous solvent was diethylether. All intensities were scaled to the signal of GaAs surface exposed to etch A.

\begin{tabular}{|c|c|}
\hline Treatment & $\mathrm{PL}$ intensity \\
\hline \multicolumn{2}{|l|}{ Section A } \\
\hline 1.0-M Na ${ }_{2} \mathrm{~S} \cdot 9 \mathrm{H}_{2} \mathrm{O}(p \mathrm{H} 13-14)$ & $270^{a}$ \\
\hline 1.0-M NaHS $\cdot\left(\mathrm{H}_{2} \mathrm{O}\right)_{x}(\mathrm{aq})$ & $410^{\mathrm{a}}$ \\
\hline $0.10-\mathrm{M} \mathrm{NaHS} \cdot\left(\mathrm{H}_{2} \mathrm{O}\right)_{x}(p \mathrm{H} 10.8)$ & 120 \\
\hline $0.10-\mathrm{M}$ NaHS $\cdot\left(\mathrm{H}_{2} \mathrm{O}\right)_{x}(p \mathrm{H} 7.8)$ & 240 \\
\hline $0.10-\mathrm{M} \mathrm{NaHS} \cdot\left(\mathrm{H}_{2} \mathrm{O}\right)_{x}(p \mathrm{H} 1.54)$ & 20 \\
\hline \multicolumn{2}{|l|}{ Section B } \\
\hline $\mathrm{H}_{2} \mathrm{O}(l)$ & 1 \\
\hline $0.1-\mathrm{M} \mathrm{NaOH}(\mathrm{aq})$ & 1 \\
\hline $1.0-\mathrm{M} \mathrm{KOH}(\mathrm{aq})$ & $40^{\mathrm{a}}$ \\
\hline \multicolumn{2}{|l|}{ Section $C$} \\
\hline $1.0-\mathrm{M} \mathrm{Na}_{2} \mathrm{~S} \cdot 9 \mathrm{H}_{2} \mathrm{O}(p \mathrm{H}$ 13.7) & 280 \\
\hline $0.10-\mathrm{M} \mathrm{Na}{ }_{2} \mathrm{~S} \cdot 9 \mathrm{H}_{2} \mathrm{O}(p \mathrm{H} 12.7)$ & 220 \\
\hline $0.010-\mathrm{M} \mathrm{Na} 2 \mathrm{~S} \cdot 9 \mathrm{H}_{2} \mathrm{O}(p \mathrm{H} 12.5)$ & 30 \\
\hline $0.0010-\mathrm{M} \mathrm{Na}_{2} \mathrm{~S} \cdot 9 \mathrm{H}_{2} \mathrm{O}(p \mathrm{H} 12.5)$ & 1 \\
\hline \multicolumn{2}{|l|}{ Section D } \\
\hline Etch A, 1.0-M Na $2 \mathrm{~S} \cdot 9 \mathrm{H}_{2} \mathrm{O}$ (aq) & 270 \\
\hline Etch $\mathrm{B}, 1.0-\mathrm{M} \mathrm{Na}_{2} \mathrm{~S} \cdot 9 \mathrm{H}_{2} \mathrm{O}(\mathrm{aq})$ & 270 \\
\hline Etch A, $1.0-\mathrm{M} \mathrm{Na}_{2} \mathrm{~S} \cdot 9 \mathrm{H}_{2} \mathrm{O}$ (aq) & 270 \\
\hline Etch $\mathrm{C}, 1.0-\mathrm{M} \mathrm{Na} 2 \mathrm{~S} \cdot 9 \mathrm{H}_{2} \mathrm{O}$ (aq) & 280 \\
\hline Etch A, 1.0-M $\mathrm{HSC}_{6} \mathrm{H}_{4} \mathrm{Cl}$ & 140 \\
\hline Etch B, 1.0-M $\mathrm{HSC}_{6} \mathrm{H}_{4} \mathrm{Cl}$ & 90 \\
\hline \multicolumn{2}{|l|}{ Section $\mathbf{E}$} \\
\hline 1.0-M Na $\mathrm{Na}_{2} \mathrm{~S} \cdot 9 \mathrm{H}_{2} \mathrm{O}(\mathrm{aq})$ & 240 \\
\hline 1 drop $\mathrm{H}_{2} \mathrm{O}$ & 80 \\
\hline rinse & 30 \\
\hline \multicolumn{2}{|l|}{ Section $\mathbf{F}$} \\
\hline $\mathrm{HSCH}_{2} \mathrm{CH}_{2} \mathrm{SH}(l)$ & $170^{\mathrm{a}}$ \\
\hline $\mathrm{CH}_{3} \mathrm{SCH}_{3}(l)$ & $2^{\mathrm{a}}$ \\
\hline
\end{tabular}

${ }^{a}$ Experiments used in Fig. 1. Data in the table are the representative average values for the particular treatment, while data in Fig. 2 represent one particular trial.

ues of 6.9 and $18,{ }^{34}$ the predominant species for $7<p \mathrm{H}$ $<15$ is therefore $\mathrm{HS}^{-}(\mathrm{aq})$, with only extremely low levels of $\mathrm{S}^{2-}(\mathrm{aq})$ present in the $p \mathrm{H}=7.8$ solutions. If $\mathrm{S}^{2-}(\mathrm{aq})$ were the only species involved in reaction with GaAs, the steady state PL increase would be expected to be pronounced only in the most basic aqueous solutions. The data of Table I do not support this hypothesis, and therefore imply that the predominant reactive species is not $\mathbf{S}^{2-}$ (aq) but is $\mathrm{HS}^{-}$(aq).

To determine if the GaAs surface recombination properties were influenced by the variation in proton activity from the unbuffered $1.0-\mathrm{M} \mathrm{Na} 2 \mathrm{~S} \cdot 9 \mathrm{H}_{2} \mathrm{O}(\mathrm{aq})(p \mathrm{H} \approx 14)$ solution to the $p \mathrm{H}=7.8,0.1-\mathrm{M} \mathrm{NaHS} \cdot\left(\mathrm{H}_{2} \mathrm{O}\right)_{x}$ solution, additional experiments were performed without any sulfides present in solution. Neutral water did not increase the PL signal over the value obtained from an etched GaAs surface (Table I, Sec. B). Also, exposure of the 1.0- $\mu \mathrm{m}$ epilayer GaAs samples to $0.1-\mathrm{M} \mathrm{NaOH}(\mathrm{aq})$ did not cause any enhancement in PL, while exposure to $0.10-\mathrm{M}$ 
TABLE II. PL intensity (arbitrary units) at $874 \mathrm{~nm}$ for bulk $N_{D}=10^{17}$ $\mathrm{cm}^{-3}(100) n$-GaAs samples. The excitation source was an Ar-ion laser at $514 \mathrm{~nm}$. The exposure time was $30 \mathrm{~min}$ and the nonaqueous solvent was diethylether. PL values are normalized to the value obtained for a surface which had only been exposed to etch $\mathrm{A}$.

\begin{tabular}{|c|c|}
\hline Treatment & PL intensity \\
\hline \multicolumn{2}{|l|}{ Section A } \\
\hline $1.0-\mathrm{M} \mathrm{Na}_{2} \mathrm{~S} \cdot 9 \mathrm{H}_{2} \mathrm{O}(\mathrm{aq})$ & 7 \\
\hline 1.0-M Na $\mathrm{S} \cdot 9 \mathrm{H}_{2} \mathrm{O}$ (aq) (in glove bag) & 5 \\
\hline 1.0-M Na $25 \cdot 9 \mathrm{H}_{2} \mathrm{O}+1-\mathrm{M} \mathrm{S}^{0}(\mathrm{aq})$ & 9 \\
\hline \multicolumn{2}{|l|}{ Section B } \\
\hline Etch $A, 1.0-\mathrm{M} \mathrm{Na}_{2} \mathrm{~S}(\mathrm{aq})$ & $1.7^{\mathrm{a}}$ \\
\hline Etch B, 1.0-M Na $\mathrm{S}_{2} \mathrm{Saq}$ ) & 1.7 \\
\hline Etch $\mathrm{A}, 1.0-\mathrm{M} \mathrm{HSC} \mathrm{H}_{6} \mathrm{H}_{4} \mathrm{Cl}$ & 1.5 \\
\hline Etch $\mathrm{B}, 1.0-\mathrm{M} \mathrm{HSC} \mathrm{H}_{6} \mathrm{H}_{4} \mathrm{Cl}$ & 1.5 \\
\hline Etch A, 1.0-M HSCH${ }_{2} \mathrm{CH}_{2} \mathrm{SH}$ & 1.5 \\
\hline Etch B, 1.0-M $\mathrm{HSCH}_{2} \mathrm{CH}_{2} \mathrm{SH}$ & 1.5 \\
\hline \multicolumn{2}{|l|}{ Section C } \\
\hline 1.0-M Na $2 \mathrm{~S}(30 \mathrm{~min})(\mathrm{aq})$ & 5 \\
\hline rinse with $\mathrm{H}_{2} \mathrm{O}$ & 3 \\
\hline \multicolumn{2}{|l|}{ Section D } \\
\hline $1.0-\mathrm{M} \mathrm{KSCN}(\mathrm{aq})$ & 0.9 \\
\hline $1.0-\mathrm{M} \mathrm{KCN}(\mathrm{aq})$ & 1 \\
\hline \multicolumn{2}{|l|}{ Section $\mathrm{E}$} \\
\hline $\mathrm{HSCH}_{2} \mathrm{CH}_{2} \mathrm{SH}(l)$ & 6 \\
\hline 3-methyl thiophene $(l)$ & 1 \\
\hline DMSO $(l)$ & 1 \\
\hline
\end{tabular}

${ }^{2} \mathrm{GaAs}$ samples used for the experiments in Sec. $\mathbf{B}$ had nominally the same dopant density, but had a lower bulk lifetime and were not from the same supplier as the GaAs used for all other experiments in this table.

NaHS $\cdot\left(\mathrm{H}_{2} \mathrm{O}\right)_{x}$ solutions did result in a large PL signal. These experiments clearly indicated that the predominant surface passivation effects were related primarily to the sulfur component of the aqueous solutions. Exposure to 1.0-M KOH(aq) did yield modest improvements in the GaAs PL signal (Fig. 1; Table I, Sec. B), but these PL signals were transient in nature and were not of the same magnitude as those obtained after exposure to either the 0.10 or $1.0-\mathrm{M}$ aqueous sulfide solutions of $7<p \mathrm{H}<14$.

Several control experiments were performed to determine whether $\mathrm{S}^{2-}(\mathrm{aq})$, which is present in extremely low concentrations in $0.10-\mathrm{M} \mathrm{NaHS} \cdot\left(\mathrm{H}_{2} \mathrm{O}\right)_{x}$ solutions of $p \mathrm{H}$ $<10$, could influence the GaAs surface recombination rate. In $0.10-\mathrm{M} \mathrm{NaOH}(\mathrm{aq})$, when the total sulfur concentration (as $\mathrm{HS}^{-}, \mathrm{S}^{2-}$, etc.) was lowered to $1 \mathrm{mM}$, no increase in the GaAs PL intensity was observed relative to the etched and air-exposed GaAs surface (Table I, Sec. C). In contrast, as described above, a 200 -fold increase in PL intensity was readily observed after immersion of $1.0-\mu \mathrm{m}$ GaAs epilayer samples into a $p \mathrm{H}=7.8,0.1-\mathrm{M}$ NaHS $\left(\mathrm{H}_{2} \mathrm{O}\right)_{x}(\mathrm{aq})$ solution. Since the equilibrium concentration of $\mathbf{S}^{2-}(\mathrm{aq})$ in the $0.10-\mathrm{M} \mathrm{NaOH}(\mathrm{aq}), 1.0-\mathrm{mM}$ $\mathrm{Na}_{2} \mathrm{~S}(\mathrm{aq})$ solution was 1000 times higher than that in the $0.10-\mathrm{M}$ total sulfur $p \mathrm{H}=7.8$ solution [where $\left.\mathrm{S}^{2-}(\mathrm{aq})=10^{-10} \mathrm{M}\right]$, these data indicate that $\mathrm{S}^{2-}(\mathrm{aq})$ alone is not responsible for the passivation effect on GaAs surfaces.

b. $p H$ dependence of the steady-state photoluminescence intensity: $\mathrm{H}_{2} \mathrm{~S}$ vs $\mathrm{HS}^{-}$(aq). Some prior work has described the formation of robust $\mathrm{Ga}_{2} \mathrm{~S}_{3}$ overlayers on $\mathrm{GaAs}$ after exposure to "activated" $\mathrm{H}_{2} \mathrm{~S}(\mathrm{~g}) ;{ }^{13}$ therefore, the activity of $\mathrm{H}_{2} \mathrm{~S}(\mathrm{~g})$ and $\mathrm{H}_{2} \mathrm{~S}(\mathrm{aq})$ must also be considered in evaluating the role of $\mathrm{HS}^{-}$(aq). Exposure to 1-atm $\mathrm{H}_{2} \mathrm{~S}(\mathrm{~g}$ ) (made from acidification of solid NaHS $\left(\mathrm{H}_{2} \mathrm{O}\right)_{x}$ or to $0.1-\mathrm{M}$ $\mathrm{H}_{2} \mathrm{~S}(\mathrm{aq})$ [made from acidification of $0.1-\mathrm{M}$ NaHS $\left.\left(\mathrm{H}_{2} \mathrm{O}\right)_{x}(\mathrm{aq})\right]$ produced some increase in the GaAs PL signal, but did not produce the 200 -fold signal enhancements on $1.0-\mu \mathrm{m}$ epilayer GaAs samples that were obtained from $\mathrm{HS}^{-}$(aq) solutions (Table I, Sec. A; Fig. 1). When the GaAs samples were exposed to dry $\mathrm{H}_{2} \mathrm{~S}(\mathrm{~g})$ from a lecture bottle, no PL signal increase was observed over timescales comparable to those used for the aqueous sulfide solutions. Longer exposure times to $\mathrm{H}_{2} \mathrm{~S}(\mathrm{~g})$ in the presence of some water vapor did produce a modest PL signal increase over about a 10 -min time period, but again these signals were not of the magnitude obtained from immersion into the $\mathrm{Na}_{2} \mathrm{~S} \cdot 9 \mathrm{H}_{2} \mathrm{O}(\mathrm{aq})$ or $\mathrm{NaHS}$ (aq) solutions. These experiments indicate that the predominant surface passivation effects of $\mathrm{Na}_{2} \mathrm{~S} \cdot 9 \mathrm{H}_{2} \mathrm{O}(\mathrm{aq})$ solutions do not arise solely from $\mathrm{H}_{2} \mathrm{~S}$ chemisorption, but likely involve the aqueous $\mathrm{HS}^{-}$ion, which is the dominant aqueous species over the $7<p \mathrm{H}<14$ range in which the large PL enhancements are observed.

c. Role of the sulfur oxidation state on the steady-state photoluminescence intensity. The partial oxidation of aqueous chalcogenide anions by oxygen is well-documented, ${ }^{35}$ and must also be considered as a source of the surfaceactive sulfur species. Solutions of $1.0-\mathrm{M} \mathrm{Na} \mathrm{Na}_{2} \mathrm{~S}(\mathrm{aq})$ prepared from commercial $\mathrm{Na}_{2} \mathrm{~S} \cdot 9 \mathrm{H}_{2} \mathrm{O}(\mathrm{s})$ turned yellow upon acidification, indicating the formation of polysulfide species. This effect was minimized with the 0.10-M $\mathrm{NaHS} \cdot\left(\mathrm{H}_{2} \mathrm{O}\right)_{x}$ solutions described above by using deaerated solutions and added $\mathrm{NaN}_{3}$ as a reductant. This is relevant because most prior investigations of the GaAs- $\mathrm{Na}_{2} \mathrm{~S} \cdot 9 \mathrm{H}_{2} \mathrm{O}$ and $\mathrm{GaAs}-\left(\mathrm{NH}_{4}\right)_{2} \mathrm{~S}$ interfaces have not indicated that precautions were taken to exclude air from the aqueous solutions used as surface treatments or sample rinses, and even in basic solutions, oxidized sulfur could provide a facile reactant for transforming either lattice $\mathrm{As}_{\mathrm{GaAs}}$ or $\mathrm{As}^{0}$ into products such as $\mathrm{As}_{2} \mathrm{~s}_{3}$.

Addition of elemental sulfur to $1.0-\mathrm{M} \mathrm{Na}_{2} \mathrm{~S} \cdot 9 \mathrm{H}_{2} \mathrm{O}(\mathrm{aq})$ solutions was observed to yield only minor changes in the PL signal of bulk $N_{d}=10^{17} \mathrm{~cm}^{-3} \mathrm{GaAs}$ (Table II, Sec. A). This experiment suggested that either oxidized sulfur was not the source of the GaAs PL improvement, or that trace levels of oxidized sulfur from the $\mathrm{Na}_{2} \mathrm{~S} \cdot 9 \mathrm{H}_{2} \mathrm{O}(\mathrm{s})$ were sufficient to produce the maximum PL effect on $\mathrm{GaAs}$ surfaces. To test the latter possibility, a series of experiments was performed with solutions that contained minimal oxidized sulfur. Deaerated $S^{0}$-free solutions prepared from 1.0-M NaHS(aq) and $\mathrm{NaN}_{3}$ (see Experimental Sec. B) yielded PL signals on $1.0-\mu \mathrm{m}$ GaAs samples that were slightly higher than those obtained from 1.0-M $\mathrm{Na}_{2} \mathrm{~S} \cdot 9 \mathrm{H}_{2} \mathrm{O}$ (aq) (Table I, Sec. A). Another set of exper- 
iments with bulk $N_{d}=10^{17} \mathrm{~cm}^{-3} \mathrm{GaAs}$ was performed in a glove bag that was purged with $\mathrm{N}_{2}(\mathrm{~g})$. For these experiments, the etching and $1.0-\mathrm{M} \mathrm{Na} \mathrm{Na}_{2} \mathrm{~S} \cdot 9 \mathrm{H}_{2} \mathrm{O}$ (aq) solutions. were deaerated before use, the $\mathrm{GaAs}$ samples were etched and manipulated anaerobically, and a polymer film was used to cover the $\mathrm{Na}_{2} \mathrm{~S}$ coating and to prevent oxidation during subsequent handling steps. Despite these precautions, no significant difference in the steady-state GaAs PL increase was observed relative to experiments performed when the sample was etched in air and exposed to air during transfer to the PL setup (Table II, Sec. A). These experiments seem to confirm the hypothesis that reduced sulfur in the -2 oxidation state (in the form of $\mathrm{HS}^{-}$) is the key solution component in the aqueous $\mathrm{GaAs}$ surface passivation process.

d. Role of GaAs surface composition on the steady-state photoluminescence intensity. The effects of varying the initial surface composition are also of interest, due to a potential role of $\mathrm{As}^{0}$ in GaAs surface recombination processes. ${ }^{2,5}$ For two etches used in this study (the nearstoichiometric surface etch $\mathrm{A}$, or the $\mathrm{As}^{0}$-rich surface etch $B)$, the relative change in PL intensity after exposure to 1.0-M Na $\mathrm{Na}_{2} \mathrm{~S} \cdot 9 \mathrm{H}_{2} \mathrm{O}(\mathrm{aq})$ at $p \mathrm{H}=13$ was found to be independent of the etchant procedure. This somewhat surprising result was verified for the bulk $N_{d}=10^{17} \mathrm{~cm}^{-3} \mathrm{GaAs}$ material, and for the 1.0- $\mu \mathrm{m}$ epilayer GaAs samples (Table I, Sec. D; Table II, Sec. B). Use of the oxidizing etch (etch C) also did not affect the magnitude of the PL increase for the 1.0- $\mu \mathrm{m}$ epilayer GaAs samples (Table I, Sec. D). In fact, we did not observe any systematic correlation with the initial GaAs surface composition for any of the aqueous $\mathrm{Na}_{2} \mathrm{~S} \cdot 9 \mathrm{H}_{2} \mathrm{O}$ solutions investigated in this study. The reasons for this insensitivity to initial GaAs surface composition are readily apparent from, and consistent with, the XPS analysis discussed below in Sec. III C 1.

e. Other variables affecting the GaAs photoluminescence intensity. A significant observation with respect to the XPS data is that the PL intensity resulting from all the aqueous treatments was observed to decrease after the GaAs surface was thoroughly rinsed with $\mathrm{H}_{2} \mathrm{O}$. To illustrate this observation, Table I, Sec. E and Table II, Sec. C contain PL intensity data for two types of GaAs samples that had been (a) immersed in 1.0- $\mathrm{M} \mathrm{Na}_{2} \mathrm{~S} \cdot 9 \mathrm{H}_{2} \mathrm{O}$ (aq) and dried, or (b) immersed, dried and subsequently rinsed with one drop, or a large volume, of $\mathrm{H}_{2} \mathrm{O}$. Although the $\mathrm{PL}$ signal from a bulk $N_{d}=10^{17} \mathrm{~cm}^{-3} \mathrm{GaAs}$ specimen that had been immersed in 1.0-M $\mathrm{Na}_{2} \mathrm{~S} \cdot 9 \mathrm{H}_{2} \mathrm{O}$ (aq) declined only by a factor of 2 after an extensive $\mathrm{H}_{2} \mathrm{O}$ rinse, the same procedure yielded a decrease in the PL signal by over an order of magnitude when the $1.0-\mu \mathrm{m} \mathrm{GaAs}$ epilayer sample was used. Similar behavior has been reported earlier for epilayer GaAs samples. ${ }^{1}$

The difference in PL behavior between the low-doped, thin epilayer and the highly doped bulk GaAs samples was due to the decreased bulk recombination rates, the longer radiative lifetime, and the increased ratio of surface to bulk present in the epilayer sample. The observation that the PL signal did not change substantially on a highly doped, bulk GaAs sample was not therefore sufficient to insure that the rinsing procedure did not affect the GaAs surface recombination velocity; such conclusions required the use of high purity, thin, low doped, epilayer. GaAs samples with low surface recombination velocities at the back AlGaAs/ GaAs interface. This is especially relevant to a number of prior spectroscopic studies of the bulk GaAs passivation chemistry on rinsed GaAs surfaces, in which increased PL signals on bulk, highly doped GaAs samples have been used as a check that the passivation chemistry has not been altered during the various aspects of the experimental procedure.

Aqueous solutions that contained ions other than sulfide were used to explore the possibility that a general class of large, negatively charged, aqueous ions might affect the steady-state PL intensity of GaAs surfaces. Exposure of bulk $N_{d}=10^{17} \mathrm{~cm}^{-3} \mathrm{GaAs}$ to either $1.0-\mathrm{M} \mathrm{KCN(aq)} \mathrm{or}$ 1.0-M KSCN(aq) produced no statistically significant increase in PL intensity above the value for an etched GaAs sample (Table II, Sec. D). This suggests that the large PL effects induced by the aqueous $\mathrm{HS}^{-}$solutions were not dominated merely by an electrostatically driven adsorption process, but that specific S-based chemical interactions with the GaAs surface must be invoked to explain the large PL intensity change.

\section{Organic thiols and sulfides}

The significant surface passivation properties of $\mathrm{HS}^{-}$(aq) prompted us to investigate the effects of organic thiols, thiolates, and other electron rich centers on the GaAs PL intensity. As depicted in Fig. 2, exposure of the $1.0-\mu \mathrm{m}$ GaAs epilayer sample to a variety of thiols (dissolved in diethylether solvent) yielded increases in PL that were comparable to the increase produced by $1.0-\mathrm{M}$ $\mathrm{Na}_{2} \mathrm{~S} \cdot 9 \mathrm{H}_{2} \mathrm{O}(\mathrm{aq})$. The thiol-induced changes in PL intensity were similar for either etch A or etch B on the GaAs surface (Table I, Sec. D). Similar trends in the thiol PL bchavior were evident in experiments performed on bulk $N_{d}=10^{17} \mathrm{~cm}^{-3} \mathrm{GaAs}$ samples (Table II, Secs. B and E), confirming that the surface passivation effects were not unique to low-doped, epilayer-type GaAs samples.

The efficacy of surface passivation was approximately the same for aromatic thiols, aliphatic thiols, and aliphatic dithiols, all of which showed on the order of a hundred fold increase in PL intensity for the 1.0- $\mu \mathrm{m} \mathrm{GaAs}$ epilayer samples under our standard experimental conditions. Although 1.0-M solutions of 1-butanethiol in diethylether did not yield an increase in PL comparable to that of the other thiols, this effect was readily explained by the volatility of the butanethiol (b.p. $98^{\circ}$ ); when the GaAs surface was kept in contact with the 1-butanethiol, either by continuous immersion in the liquid or by maintaining the sample above a volume of liquid 1-butanethiol, the expected PL increase was observed.

Other sulfur-containing compounds, including $\left(\mathrm{CH}_{3}\right)_{2} \mathrm{SO}$ and thiophene, were evaluated with respect to their surface-passivation properties on bulk $N_{d}=10^{17}$ $\mathrm{cm}^{-3}$ GaAs (Table II, Sec. E). These weak bases produced little or no change in the PL signal. Dimethylsulfide produced a larger PL increase than the weaker bases 


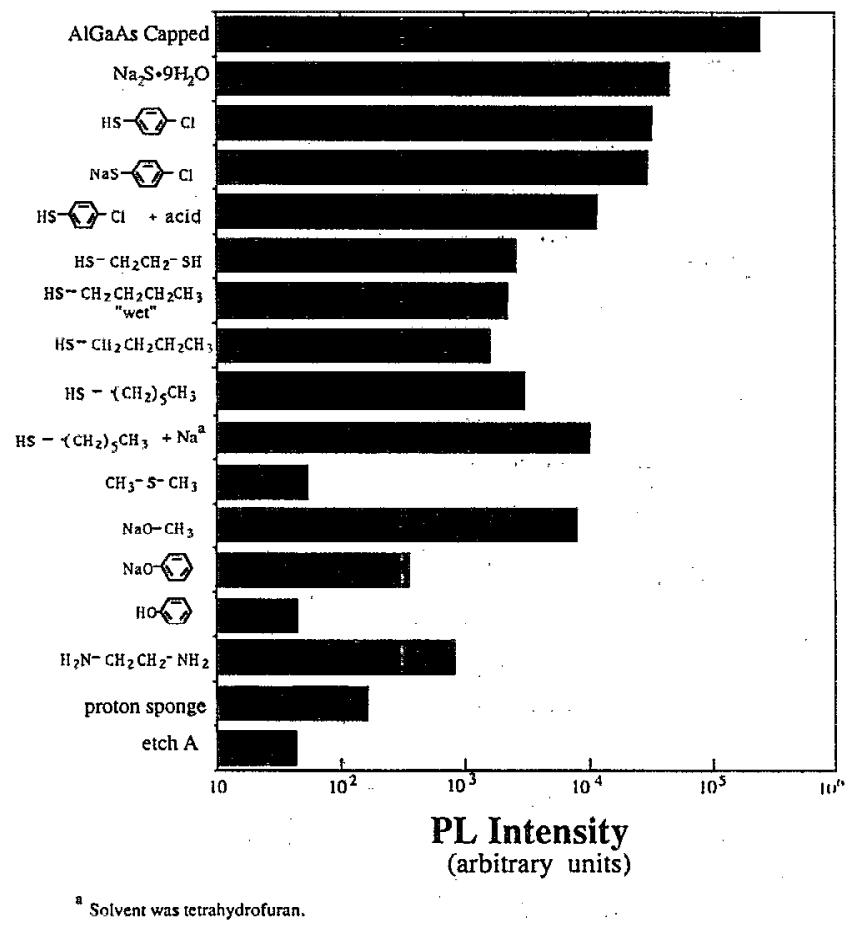

FIG. 2. Bar graph of steady-state photoluminescence intensity at $874 \mathrm{~nm}$ for $1.0-\mu \mathrm{m}$ thick epilayer (100) $n$-GaAs samples after exposure to various nonaqueous solutions. The excitation source was a $\mathrm{He}-\mathrm{Ne}$ laser at 632.8 $\mathrm{nm}$. The result for a $1.0-\mathrm{M} \mathrm{Na}_{2} \mathrm{~S} \cdot 9 \mathrm{H}_{2} \mathrm{O}$ (aq) solution is given for comparison. Unless otherwise indicated, all species were $1.0 \mathrm{M}$ in diethylether, except for the "wet" 1-butanethiol experiment which was done in the pure liquid and $\mathrm{NaOCH}_{3}$ which was $1.0 \mathrm{M}$ in methanol.

$\left(\mathrm{CH}_{3}\right)_{2} \mathrm{SO}$ or thiophene, but the magnitude of the $\left(\mathrm{CH}_{3}\right)_{2}$ S-induced PL increase was much smaller than that obtained with simple alkyl- or aryl-thiols (Fig. 2 and Table I, Sec. F). This trend is consistent with the ligation properties of these compounds towards various Lewis acid centers, as well as with trends in their equilibrium constants towards protonation. ${ }^{36,37}$

\section{Other organic bases}

Surprisingly, some nonsulfur Brønsted bases also produced substantial, persistent, increases in the GaAs PL signal. Methoxide and phenoxide both yielded significant PL increases, with the steady-state PL increase after exposure to $\mathrm{OCH}_{3}^{-}$being comparable to that of the thiols and only slightly lower than that observed after contact with aqueous $1.0-\mathrm{M} \mathrm{Na} 25 \cdot 9 \mathrm{H}_{2} \mathrm{O}$ solutions. The PL signal was also stable over time, unlike the behavior observed after exposure to $1.0-\mathrm{M} \mathrm{KOH}(\mathrm{aq})$ solutions. In contrast, the sterically hindered nitrogen base, 1.8-bis (dimethylamino)naphthalene, or "proton sponge," yielded only a small increase in PL intensity. The beneficial effect of the oxygen bases were not anticipated in view of the previously proposed role for As-S (and/or Ga-S) species in the surface passivation mechanism. ${ }^{12,15}$ A consistent explanation for the $\mathrm{OCH}_{3}^{-}$and phenoxide $\mathrm{PL}$ response was obtained from time-resolved PL experiments that are discussed in the next section.

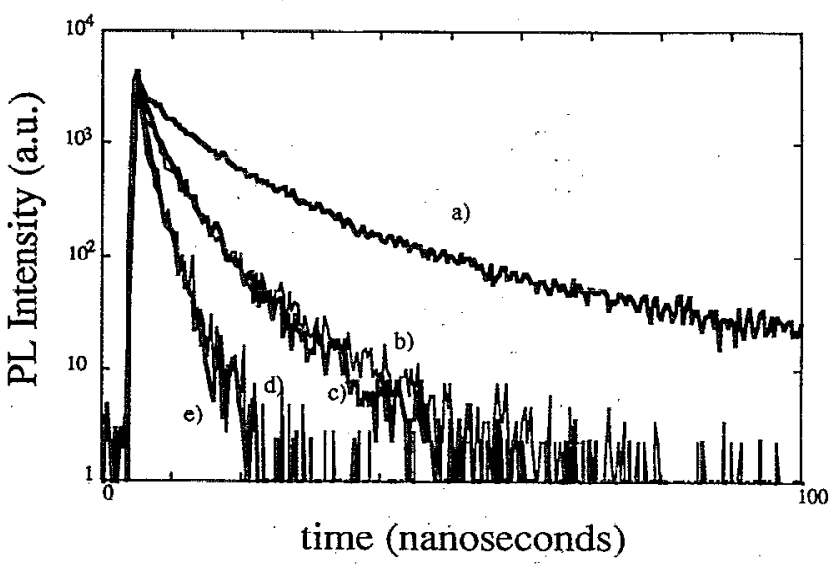

FIG. 3. Time-resolved photoluminescence decay curves of $2.8-\mu \mathrm{m}$-thick epilayer GaAs samples taken at $880 \mathrm{~nm}$. The excitation source was a Nd:YAG pumped dye laser providing light at $685 \mathrm{~nm}$. (a) $\mathrm{Al}_{0.3} \mathrm{Ga}_{0.7} \mathrm{As}$ capped GaAs sample, as grown. (b) $\mathrm{Al}_{0.3} \mathrm{Ga}_{0.7} \mathrm{As}$ cap etched off with $0.05 \% \mathrm{Br}_{2}$ in methanol and $\mathrm{GaAs}$ sample immersed into in $1.0-\mathrm{M}$ $\mathrm{Na}_{2} \mathrm{~S} \cdot 9 \mathrm{H}_{2} \mathrm{O}$ (aq) for $30 \mathrm{~min}$. (c) Etched GaAs sample immersed into 1.0-M 4-Cl-thiophenol in $\mathrm{CCl}_{4}$ for $30 \mathrm{~min}$. (d) Etched $\mathrm{GaAs}$ sample immersed into $1.0-\mathrm{M} \mathrm{NaOCH}_{3}$ in methanol for $30 \mathrm{~min}$. (e) GaAs sample only exposed to etch $\mathrm{A}$.

\section{B. Time-resolved photoluminescence}

To further understand the mechanism of surface passivation, time-resolved luminescence studies were conducted under high level injection conditions. Since the bands are flattened promptly after the laser excitation pulse, changes in the high level injection PL signal should be primarily due to variation in the density and capture cross section of surface traps, with changes in the equilibrium band bending exerting only a minor effect on either the high level injection PL intensity or the PL decay time. Because the low level injection PL intensity is affected both by changes in $S$ and in the equilibrium surface Fermi level, ${ }^{38}$ the conversion of steady-state $P L$ intensities into low level $S$ values is not straightforward; therefore, $S$ was instead extracted from the high injection, time-resolved data. ${ }^{16,18,39}$

Representative time-resolved PL data for several different GaAs surface treatments are shown in Fig. 3. These data were taken at a higher injection level and over a shorter time period than the radio-frequency decay measurements of Yablonovitch et al..$^{\text {1c }}$ The surface recombination velocity of the AlGaAs/GaAs interface has been determined previously to be $100-500 \mathrm{~cm} \mathrm{~s}^{-1}$ (Refs. 1, 29(a), 40); thus, in our experiments, the PL decay obscrved for intact $\mathrm{Al}_{0.3} \mathrm{Ga}_{0.7}$ As capping layer (yielding a best fit to $S=500 \mathrm{~cm} \mathrm{~s}^{-1}$ ) served as an excellent validation of our digital simulation method for these PL decay experiments. The most rapid PL decays were recorded for an etched, uncapped, air-exposed, GaAs surface, which gave a best fit $S$ of $2 \times 10^{5} \mathrm{~cm} \mathrm{~s}^{-1}$. The GaAs/air interface has been shown previously to have a surface recombination velocity of $>10^{5} \mathrm{~cm} \mathrm{~s}^{-1}, 1,2,40$ which was consistent with both the qualitative and quantitative PL results obtained in this study (Fig. 3). The low $S$ value for the GaAs/ 
$\mathrm{Al}_{0.3} \mathrm{Ga}_{0.7} \mathrm{As}$ interface and high $S$ value for the GaAs/air interface served as benchmarks for determining the surface recombination velocity of the other, chemically based, surface treatments.

As displayed in Fig. 3, the various chemical treatments of $\mathrm{GaAs}$ surfaces yielded decay times that were between these two extremes of $S$. While none of the chemical sur face treatments yielded PL decay times as long as those observed with the $\mathrm{Al}_{0.3} \mathrm{Ga}_{0.7}$ As capping layer, exposure to 1.0-M Na $2 \mathrm{~S} \cdot 9 \mathrm{H}_{2} \mathrm{O}$ (aq) clearly produced an interface with a lower surface recombination velocity than that obtained from the unpassivated, air-exposed, GaAs surface. Best fits of the PL decays yielded a surface recombination velocity of $7 \times 10^{4} \mathrm{~cm} \mathrm{~s}^{-1}$ for this interface. Analysis of the PL decays after exposure to 4-Cl-thiophenol also yielded a value of $7 \times 10^{4} \mathrm{~cm} \mathrm{~s}^{-1}$. In contrast, exposure to $1.0-\mathrm{M}$ $\mathrm{NaOCH}_{3}$ in $\mathrm{CH}_{3} \mathrm{OH}$ yielded essentially the same decay time as the air-exposed surface, $\left(S \approx 2 \times 10^{5} \mathrm{~cm} \mathrm{~s}^{-1}\right)$. These data clearly indicate that increases in the steadystate PL signal do not necessarily correlate with decreases surface recombination rates under high injection conditions.

The time-resolved PL results reveal that the steadystate PL improvement from exposure to $\mathrm{OCH}_{3}^{-}$was predominantly due to a shift in the equilibrium band bending, as opposed to a reduction in the inherent surface state recombination rates. This system therefore comprises a separate type of molecule that improves steady-state GaAs PL signals without concomitant decreases in high-level surface recombination velocity, and illustrates the variety of chemical mechanisms that can lead to changes in the GaAs steady-state PL intensity.

\section{X-ray photoelectron spectroscopy}

\section{Etched GaAs surfaces}

A high-energy resolution, small spot XPS instrument was used to obtain chemical information on the GaAs surface composition. (100)-oriented GaAs samples were exposed to three different etching procedures (etch A, B, or C) in order to obtain a range of initial surface stoichiometries. The As $3 d$ regions of the XPS spectra for these three surfaces are displayed as the dashed lines in Figs. $4(a)-4(c),{ }^{41}$ and the corresponding As $2 p$ regions are the dashed lines in Figs. 4(d)-4(f). These spectra were normalized relative to the intensity of the $\mathrm{As}_{\mathrm{GaAs}}$ lattice peak in the As $3 d$ region. To provide background for the changes observed after exposure to the various chemical reagents, the important features of the XPS spectra for each etch are discussed below.

a. XPS spectra of the $\mathrm{Br}_{2}-\mathrm{CH}_{3} \mathrm{OH} / \mathrm{KOH}$ etched $\mathrm{GaAs}$ surface. Etch $\mathrm{A}$ has been previously studied by Aspnes and Stocker using spectroscopic ellipsometry ${ }^{22}$ and by Tufts $e t a l .^{23}$ using XPS. If exposure to air is minimized, this etching procedure has been shown to leave a minimally oxidized, near stoichiometric, GaAs surface. This behavior was apparent in the data depicted in Fig. 4(a) (dashed curve). $\mathrm{As}_{\mathrm{GaAs}}$ signals in the As $3 d$ region were apparent as the As $3 d_{5 / 2}$ peak at $41.2( \pm 0.3) \mathrm{eV}$ with a
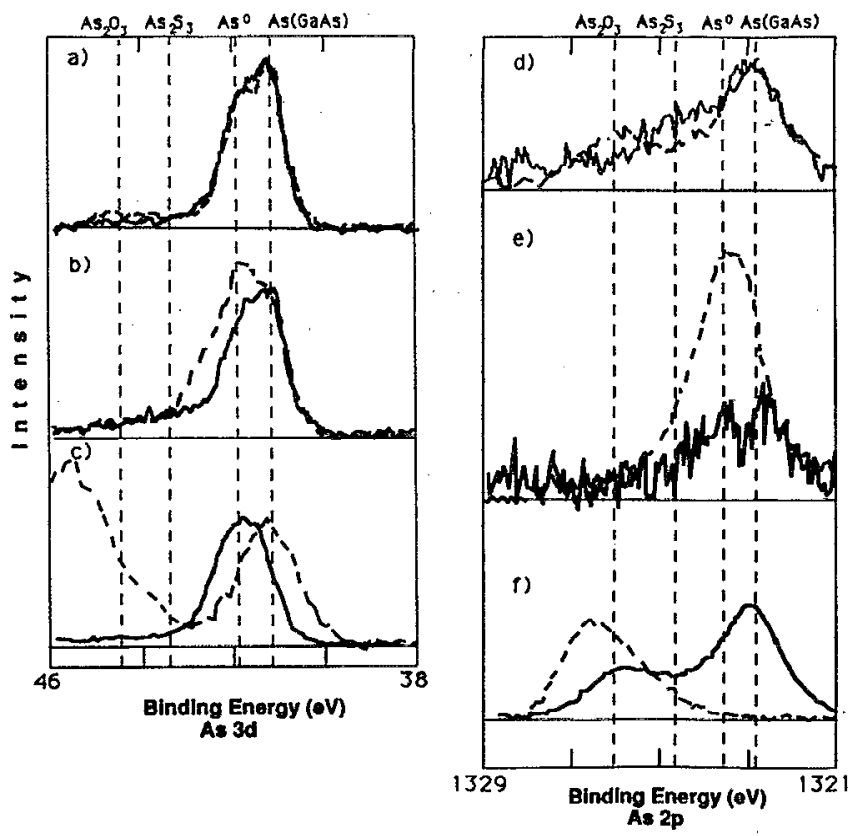

FIG. 4. As $3 d$ and $2 p$ XP spectra for bulk $10^{17}$-doped (100) $n$-GaAs. The dashed lines are the spectra for the freshly etched sample, and the solid lines are after immersion into $1.0-\mathrm{M} \mathrm{Na} \mathrm{N}_{2} \mathrm{~S} \cdot 9 \mathrm{H}_{2} \mathrm{O}(\mathrm{aq})$ for $30 \mathrm{~min}$ and extensive rinsing with $\mathrm{H}_{2} \mathrm{O}$. Panel (a) displays the As $3 d$ region for a sample that had been exposed to etch $\mathbf{A}$ (dashed line), and for another sample that had been etched and then exposed to $1.0-\mathrm{M} \mathrm{Na} \mathrm{Na}_{2} \mathrm{~S} \cdot 9 \mathrm{H}_{2} \mathrm{O}$ (solid line). Panel (b) displays the As $3 d$ region for a sample that had been exposed to etch $\mathbf{B}$ (dashed line), and for another sample that had been etched and then exposed to $1.0-\mathrm{M} \mathrm{Na}{ }_{2} \mathrm{~S} \cdot 9 \mathrm{H}_{2} \mathrm{O}$ (solid line). Panel (c) displays the As $3 d$ region for a sample that had been exposed to etch $C$ (dashed line), followed by subsequent exposure of this same sample to 1.0-M Na $2 \mathrm{~S} \cdot 9 \mathrm{H}_{2} \mathrm{O}$ (solid line). Panel (d) shows the As $2 p$ region for the samples of panel (a). Panel (e) shows the As $2 p$ region for the samples of panel (b). Panel (f) shows the As $2 p$ region for the samples of panel (c). All spectra were collected with a monochromatic XPS source under rigorously anaerobic conditions, except for the spectra in panels (c) and (f).

doublet splitting of $0.7 \mathrm{eV}$, and $\mathrm{As}_{\mathrm{GaAs}} 2 p_{3 / 2}$ signals were apparent as a peak at $1322.9( \pm 0.2) \mathrm{eV}$. The Ga $3 d$ region (not shown) displayed the expected peak for $\mathrm{Ga}_{\mathrm{GaAs}}$ at $19.3( \pm 0.3) \mathrm{eV}$. Although the calculated elemental ratio of $A s_{\mathrm{GaAs}}$ to $\mathrm{Ga}_{\mathrm{GaAs}}$ was not precisely unity (Table III), no oxidized Ga, little oxidized As, and no other significant impurities (other than adventitious carbon and oxygen from adsorbed water) were detected on this surface. Specifically, the lack of detectable peaks at $20.3 \mathrm{eV}$ in the $\mathrm{Ga}$ $3 d$ region and at $44.3 \mathrm{eV}$ in the As $3 d$ region (Fig. 4, Table III) indicated that the $\mathrm{Ga}_{2} \mathrm{O}_{3}$ and $\mathrm{As}_{2} \mathrm{O}_{3}$ coverages were less than $1 \times 10^{-10} \mathrm{~mol} \mathrm{~cm}^{-2}$ on this sample; the only evidence for oxidation was the small peak at $1326.0 \mathrm{eV}$ in the surface-sensitive As $2 p$ region [Fig. 4(d)].

The presence of elemental $A s^{0}$ was also of concern, due to its importance in various proposed GaAs surface passivation schemes. Excess elemental As has been observed to exhibit an XPS peak at $41.8( \pm 0.3) \mathrm{eV}$ in the As $3 d$ region; ${ }^{24}$ thus, the small chemical shift difference between $\mathrm{As}^{0}$ and lattice $\mathrm{As}_{\mathrm{GaAs}}$ precluded obtaining a distinct peak for $A s^{0}$ using the available XPS instrumentation. However, the coverage of elemental $A s^{\circ}$ can be determined from the $A s^{0}$ contribution to the intensity of the higher binding en- 
TABLE III. XPS Data for GaAs exposed to aqueous sodium sulfide solutions.

\begin{tabular}{|c|c|c|c|c|c|c|c|c|c|c|c|c|c|c|c|c|c|c|c|c|c|}
\hline \multirow[b]{2}{*}{ Sample } & \multirow[b]{2}{*}{$\begin{array}{l}x-r a y^{2} \\
\text { source }\end{array}$} & \multicolumn{3}{|c|}{$\mathrm{Ga} 3 d$} & \multicolumn{2}{|c|}{$\mathrm{Ga} 2 p$} & \multicolumn{7}{|c|}{ As $3 d$} & \multicolumn{4}{|c|}{ As $2 p$} & \multicolumn{4}{|c|}{ S 2s } \\
\hline & & $\begin{array}{c}\mathrm{Ga} \\
\text { (GaAs) } \\
\mathrm{eV}\end{array}$ & $\begin{array}{c}\mathrm{Ga} \\
\left(\mathrm{Ga}_{2} \mathrm{O}_{3}\right) \\
\mathrm{eV}\end{array}$ & $\begin{array}{c}\Gamma \\
\left(\mathrm{Ga}_{2} \mathrm{O}_{3}\right) \\
\mathrm{mol} / \mathrm{cm}^{2} \\
\times 10^{9}\end{array}$ & $\begin{array}{c}\mathrm{Ga} \\
(\mathrm{GaAs}) \\
\mathrm{eV}\end{array}$ & $\begin{array}{c}\mathrm{Ga} \\
\left(\mathrm{Ga}_{2} \mathrm{O}_{3}\right) \\
\mathrm{eV}\end{array}$ & $\begin{array}{c}\text { As } \\
\text { (GaAs) } \\
\mathrm{eV}\end{array}$ & $\begin{array}{c}\mathrm{As} \\
\left(\mathrm{As}_{2} \mathrm{O}_{3}\right) \\
\mathrm{eV}\end{array}$ & $\begin{array}{c}\mathrm{T} \\
\left(\mathrm{As}_{2} \mathrm{O}_{3}\right) \\
\mathrm{mol} / \mathrm{cm}^{2} \\
\times 10^{9}\end{array}$ & $\begin{array}{c}\text { As } \\
\left(A s^{10}\right) \\
e V\end{array}$ & $\begin{array}{c}\Gamma \\
\left(\mathrm{As}^{0}\right) \\
\mathrm{mol} / \mathrm{cm}^{2} \\
\times 10^{9}\end{array}$ & $\begin{array}{c}\text { As } \\
\left(\mathbf{A s}_{x} \mathbf{S}_{y}\right) \\
\mathrm{eV}\end{array}$ & $\begin{array}{c}r \\
\left(\mathrm{As}_{x} \mathrm{~S}_{y}\right) \\
\mathrm{mol} / \mathrm{cm}^{2} \\
\times 10^{9}\end{array}$ & $\begin{array}{c}\text { As } \\
\text { (GaAs) } \\
\text { eV }\end{array}$ & $\begin{array}{c}\mathrm{As} \\
\left(\mathrm{As}_{2} \mathrm{O}_{3}\right) \\
\mathrm{eV}\end{array}$ & $\begin{array}{c}\text { As } \\
\left(A s^{n}\right) \\
\mathrm{eV}\end{array}$ & $\begin{array}{c}\text { As } \\
\left(A s_{x} S_{y}\right) \\
e V\end{array}$ & $\begin{array}{c}\mathrm{Ga} / \mathrm{As} \\
3 d \\
\text { region }\end{array}$ & $\mathrm{eV}$ & $\begin{array}{c}\Gamma \\
(\mathbf{S}) \\
\mathrm{mol} / \mathrm{cm}^{2} \\
\times 10^{9}\end{array}$ & $\begin{array}{l}\text { C } 1 s \\
\text { eV }\end{array}$ \\
\hline Etch $A^{c}$ & Al & 19.5 & 20.5 & 0.5 & & & 41.3 & 44,6 & 0.3 & $\cdots$ & 0.0 & $\cdots$ & 0.0 & 1323.1 & 1326.0 & $\cdots$ & $\cdots$ & 1.5 & & & 284.9 \\
\hline$+1.0-\mathrm{M} \mathrm{Na}_{2} \mathrm{~S}(30 \mathrm{~min})$ & $\mathrm{Al}$ & 18.7 & & 0.0 & 1116.4 & & 40.5 & & 0.0 & $\cdots$ & 0.0 & 42.4 & 0.2 & 1322.1 & & $\cdots$ & 1323.6 & & & & 285.9 \\
\hline Etch A & $\mathrm{Mg}$ & 19.4 & $\cdots$ & 0.0 & 1117.0 & $\cdots$ & 41.4 & 44,0 & 0.2 & $\cdots$ & $\cdots$ & $\cdots$ & 0.0 & 1322.4 & 1325.4 & $\cdots$ & $\cdots$ & 1.1 & & & 286.0 \\
\hline$+1.0 \mathrm{M} \mathrm{Na}_{2} \mathrm{~S}(30 \mathrm{~min})$ & $\mathrm{Mg}$ & 19.5 & $\cdots$ & 0.0 & 1117.1 & $\cdots$ & 41.5 & $\cdots$ & 0.0 & $\because$ & $\cdots$ & $\cdots$ & 0.0 & 1322.6 & $\cdots$ & $\cdots$ & 1324.3 & 1.4 & 225.8 & 0.2 & 286.2 \\
\hline Etch B & $\mathrm{Al}$ & 19.5 & $\cdots$ & 0.0 & 1117.2 . & 1118.3 & 41.5 & $\cdots$ & 0.0 & 42.3 & 5.1 & $\cdots$ & 0.0 & 1323.1 & $\cdots$ & 1323.8 & & 1.3 & & & 284.9 \\
\hline$+1.0-\mathrm{M} \mathrm{Na}_{2} \mathrm{~S}(60 \mathrm{~s})$ & Al & & & & : & & & & & & & & & & & & & & $162^{d}$ & $>10.4$ & 285.6 \\
\hline fresh film & & & & & $\because$ & . & & & & & & & & & & & & & & 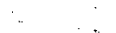 & \\
\hline+1 drop $\mathrm{H}_{2} \mathrm{O}$ & Al. & & & & 1116.3 & $\cdots$ & i & & & & & & & 1321.7 & $\cdots$ & 1322.4 & 1324.0 & & $162^{4}$ & & 285,6 \\
\hline+2 drops $\mathrm{H}_{2} \mathrm{O}$ & Al & & & & 1116.5 & $\cdots$ & 40.7 & $\cdots$ & 0.0 & 41.5 & 2.9 & $\cdots$ & 0.0 & 1321.8 & $\cdots$ & 1322.5 & 1323.9 & & & & 285.4 \\
\hline$+\mathrm{H}_{2} \mathrm{O}$ rinse & Al & 18.8 & 19.8 & 0.3 . & 1116.5 & $\cdots$ & 40.7 & $\cdots$ & 0.0 & 41.5 & 1.7 & 43.0 & 0.1 & 1322.1 & $\cdots$ & 1322.9 & 1323.7 & 0.9 & $\therefore$ & & 285.5 \\
\hline Etch B & A 1 & 19.3 & $\cdots$ & 0.0 & $\because$ & & 41.1 & $\cdots$ & 0.0 & 42.0 & 2.9 & $\cdots$ & 0.0 & & & & & 1.6 & & & 284.9 \\
\hline$+1.0-\mathrm{M} \mathrm{Na}_{2} \mathrm{~S}(60 \mathrm{~s})$ & $\mathrm{Mg}$ & 19.0 & $\cdots$ & 0.0 & & & 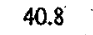 & $\cdots$ & 0.0 & $\cdots$ & $\cdots$ & $\cdots$ & 0.0 & & & & & 1.2 & 225.2 & 0.3 & 286.8 \\
\hline$\therefore$ & Al & 19.3 & 20.3 & 0.4 & & 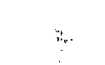 & 41.2 & $\cdots$ & 0.0 & 41.9 & 0.9 & 43.4 & 0.2 & & & & & 0.9 & & & 285.2 \\
\hline Etch B & Al & 19.2 & $\cdots$ & 0.0 & & & 41.1 & $\because$ & 0.0 & 42.0 & 2.1 & $\cdots$ & 0.0 & & & & & 1.8 & & & 285.2 \\
\hline$+1.0 \mathrm{M} \mathrm{Na} a_{2} \mathrm{~S}(1 \mathrm{~h})$ & $\mathrm{Mg}$ & $\begin{array}{l}19.2 \\
\vdots\end{array}$ & $\cdots$ & 0.0 & 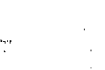 & $\because$. & 41.2 & $\cdots$ & 0.0 & $\cdots$ & $\cdots$ & $\cdots$ & 0.0 & & & & $\therefore$ & 1.2 & 225.7 & 0.4 & 285.5 \\
\hline Etch B & $\mathrm{Al}$ & 19.0 & 20.6 & 0.2 & . & $\because$ & 41.0 & 44.3 & 0.3 & 41.7 & 5.0 & $\cdots$ & 0.0 & & & $\because \because$ & & 1.8 & 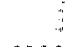 & & 285,4 \\
\hline$+1.0-\mathrm{Ma}_{2} \mathrm{~S} p \mathrm{H} 7(1 \mathrm{~h})$ & $\mathrm{Mg}$ & 19.2 & $\cdots$ & $0.0^{\prime}$ & & $\therefore$ & 41.0 & $\cdots$ & 0.0 & $\cdots$ & $\cdots$ & $\cdots$ & 0.0 & & & 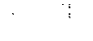 & i: & 1.3 & 226.2 & 1.3 & 285.2 \\
\hline 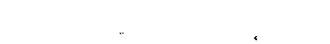 & $\mathrm{Al}$ & 19.2 & $\cdots$ & 0.0 & & . & 41.0 & $\cdots$ & 0.0 & -41.8 & 0.8 & 43.4 & 0.3 & & & . & $\ddots$ & 1.1 & & & 285.1 \\
\hline Etch C & $\mathrm{Mg}$ & 19.5 & 20.6 & 5.3 & $\cdots$ & 1118.2 & 41.3 & 45,7 & 3.8 & $\cdots$ & $\cdots$ & $\cdots$ & 0.0 & $\cdots$ & 1326.9 & $\cdots$ & $\cdots$ & 1.9 & & & 286.2 \\
\hline$+1.0 \mathrm{M} \mathrm{Na}_{2} \mathrm{~S}(30 \mathrm{~min})$ & $\mathrm{Mg}$ & 19.9 & $\ldots !$ & 0.0 & & & 41.9 & 44.7 & 0.3 & $\cdots$ & $\ldots$ & $\cdots$ & 0.0 & 1322.9 & 1326.0 & $\ldots$ & 1324.4 & 1.4 & 226.6 & 0.2 & 286.4 \\
\hline
\end{tabular}

${ }^{\mathrm{A} 1}=$ Data taken with monochromatic $\mathrm{AlK \alpha} \times \mathrm{x}$ rays $(1486.6 \mathrm{eV})$ on a Surface Science Instruments Model 100.

$\mathrm{Mg}=$ Data taken with $\mathrm{Mg} K \alpha \times$ rays $(1254 \mathrm{eV})$ on a VG Mark II.

All coverages were calculated relative to the As $3 d$ GaAs substrate peak. A value of 0.0 indicates that the level was less than $0.1 \times 10^{-9} \mathrm{~mol} / \mathrm{cm}^{2}$.

"..." indicates that the peaks were undetectable due to either sensitivity or resolution.

'The $\mathrm{Ga}$ /As ratio is based on substrate peaks and does not include oxides.

${ }^{\circ}$ Etch $\mathrm{A}=1.0-\mathrm{M} \mathrm{KOH}(15 \mathrm{~s}), 0.05 \% \mathrm{Br}_{2} /$ methanol $(15 \mathrm{~s})$, repeated 3 times and ending in $\mathrm{KOH}$.

Etch $B=$ Etch $A+30$ s 1:1:100 $\left(\mathrm{H}_{2} \mathrm{SO}_{4}: 30 \% \mathrm{H}_{2} \mathrm{O}_{2}: \mathrm{H}_{2} \mathrm{O}\right)$.

Etch $\mathrm{C}=$ Etch $\mathrm{A}+10 \mathrm{~s} 30 \% \mathrm{H}_{2} \mathrm{O}_{2}$.

Binding energy for $\mathrm{S} 2 p$ region. 
ergy peak of the $\mathrm{As}_{\mathrm{GaAs}}$ doublet. ${ }^{23,24}$ After etch $\mathrm{A}$, the $\mathrm{As}_{\mathrm{GaAs}}$ spin-orbit doublet was observed to have a 3:2 area ratio, as expected for a surface with no detectable excess elemental As [Fig. 4(a)]. ${ }^{23,24}$

b. XPS spectra of the $\mathrm{Br}_{2}-\mathrm{CH}_{3} \mathrm{OH} / \mathrm{KOH}, 1: 1: 100$ $\mathrm{H}_{2} \mathrm{SO}_{4}: \mathrm{H}_{2} \mathrm{O}_{2}: \mathrm{H}_{2} \mathrm{O}$, etched GaAs surface. Etch $\mathrm{B}$ has been shown previously by spectroscopic ellipsometry ${ }^{22}$ and by $\mathrm{XPS}^{23,24}$ to yield a surface with substantial excess elemental As ${ }^{0}$. This was clearly reflected in the XPS data of Fig. 4(b) by the additional intensity at $41.8 \mathrm{eV}$ in the $\mathrm{As} 3 d$ region and by the enhanced intensity of the As $2 p$ peak at $1323.8 \mathrm{eV}$. Spectral fitting ${ }^{23,24}$ in the As $3 d$ region was used to obtain a quantitative estimate of the $\mathrm{As}^{\mathrm{O}}$ coverage, which had a value of $5.1 \times 10^{-9} \mathrm{~mol} \mathrm{~cm}^{-2}$ for the sample of Fig. 4(b); analysis of the As $2 p$ region yielded an elemental $\mathrm{As}^{0}$ coverage of $4.7 \times 10^{-9}$. As displayed in Fig. 4(b), negligible amounts of $\mathrm{As}_{2} \mathrm{O}_{3}$ (or $\mathrm{Ga}_{2} \mathrm{O}_{3}$ ) were routinely observed when etch $\mathrm{B}$ was used and the sample was handled in an anaerobic environment.

c. XPS spectra of peroxide etched GaAs surfaces. GaAs surfaces exposed to etch $\mathrm{C}$ showed decreased absolute $\mathrm{As}_{\mathrm{GaAs}}$ and $\mathrm{Ga}_{\mathrm{GaAs}}$ peak intensities relative to those observed from GaAs samples exposed to Etch A. Additionally, a broad peak at $20.6 \mathrm{eV}$ in the $\mathrm{Ga} 3 d$ region indicated the presence of a mixture of $\mathrm{Ga}_{2} \mathrm{O}_{3}$ and $\mathrm{Ga}_{2} \mathrm{O}_{5}$, and the peaks centered at $45.7 \mathrm{eV}$ in the $\mathrm{As} 3 d$ region and at $1326.9 \mathrm{eV}$ in the As $2 p$ region indicated the presence of a mixture of $\mathrm{As}_{2} \mathrm{O}_{3}$ and $\mathrm{As}_{2} \mathrm{O}_{5}$ [Figs. 4(c) and 4(f); Table III]. This surface was clearly oxidized, as indicated by previous spectroscopic ellipsometry ${ }^{22}$ and $X^{2}{ }^{24}$ data. Unlike the previous spectra discussed above, the XPS data of Figs. 4(c) and 4(f) were obtained on a nonmonochromatic XPS instrument; thus, the lack of resolution in the $\mathrm{As}_{\mathrm{GaAs}} 3 d$ doublet region is not an inherent property of these samples, but reflects the resolution limits of the instrumentation. ${ }^{24}$ The elemental $\mathrm{As}^{\mathrm{O}}$ coverage was not of concern for this etch, so the lack of high-energy resolution XPS data in the As $3 d$ region did not preclude use of this sample for the $\mathrm{Na}_{2} \mathrm{~S} \cdot 9 \mathrm{H}_{2} \mathrm{O}$ experiments described below. The obvious differences in surface stoichiometry provided by these three different GaAs etches were exploited in our XPS investigations of the S-based surface passivation chemistry.

\section{Exposure of $\mathrm{GaAs}$ to $\mathrm{Na}_{2} \mathrm{~S} \cdot \mathbf{9 H _ { 2 }} \mathrm{O}(a q)$ solutions}

a. GaAs surface composition after exposure to 1.0-M $\mathrm{Na}_{2} \mathrm{~S} \cdot 9 \mathrm{H}_{2} \mathrm{O}(\mathrm{aq})$ and $\mathrm{a} \mathrm{H}_{2} \mathrm{O}(\mathrm{l})$ rinse. The solid lines in Figs. 4(a)-4(f) display the As $3 d$ and As $2 p$ XP spectra obtained after exposure of the etched GaAs surfaces to 1.0-M $\mathrm{Na}_{2} \mathrm{~S} \cdot 9 \mathrm{H}_{2} \mathrm{O}(\mathrm{aq})$. A striking feature of these spectra is that the three $\mathrm{Na}_{2} \mathrm{~S}$-treated $\mathrm{GaAs}$ samples had extremely similar surface compositions, despite the significant differences in initial surface stoichiometry for the three etching procedures. The 1.0-M Na $2 \mathrm{~S} \cdot 9 \mathrm{H}_{2} \mathrm{O}$ (aq) exposure removed almost all of the As and $\mathrm{Ga}$ oxides [Figs. 4(c) and 4(f); Table III] and substantially reduced the levels of $\mathrm{As}^{0}$ [Figs. 4(b) and 4(e) Table III] that were introduced by the etching steps. The only significant difference between the three final surfaces was the oxide peak evident in the As $2 p$ region of Fig. 4(f). This residual, low-level, oxide peak was
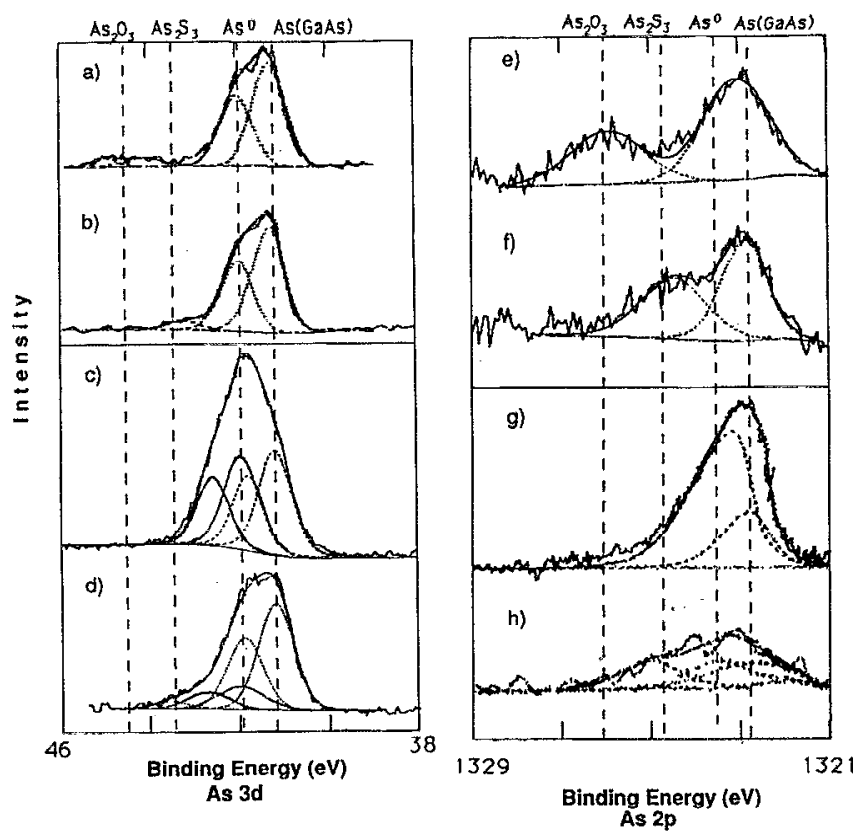

FIG. 5. Peak fits for selected As $3 d$ and $2 p$ XP spectra of Fig. 4. The As $3 d$ doublets were constrained to a ratio of $1.5: 1$ and a separation of $0.7 \mathrm{eV}$. Substrate As doublet peaks are indicated as the dashed lines in the fits, and elemental $\mathrm{As}^{\mathrm{O}}$ peaks are indicated as the solid lines. (a) As $3 d$ spectrum of etched GaAs sample from Fig. 4(a), with peak fits as shown. (b) As $3 d$ spectrum of $1.0-\mathrm{M} \mathrm{Na} 2 \mathrm{~s} \cdot 9 \mathrm{H}_{2} \mathrm{O}(\mathrm{aq})$ exposed GaAs sample of Fig. 4 (a), with peak fits as shown. (c) As $3 d$ spectrum of etched GaAs sample from Fig. 4(b), with peak fits as shown. (d) As $3 d$ spectrum of 1.0-M $\mathrm{Na}_{2} \mathrm{~S} \cdot 9 \mathrm{H}_{2} \mathrm{O}$ (aq) exposed GaAs sample of Fig. 4(b), with peak fits as shown. (e) As $2 p$ region for the sample of panel (a). (f) As $2 p$ region for the sample of panel (b). (g) As $2 p$ region for the sample of panel (c). (h) As $2 p$ region for the sample of panel (d).

observed in the surface-sensitive As $2 p$ region on this sample because unlike the XPS instrument used for Figs. 4(a), 4(b), 4(d), and 4(e) the XPS instrument used for experiment Figs. 4(c) and 4(f) did not have an anaerobic interlock to a glove box, and therefore atmospheric exposure could not be completely eliminated for this specimen.

Independent XPS experiments verified that As(III) oxides, $\mathrm{Ga}$ (III) oxides, and $\mathrm{As}^{0}$ were not removed by rinsing the $\mathrm{GaAs}$ surface with pure $\mathrm{H}_{2} \mathrm{O}$; thus, the similarity of the GaAs spectra in Figs. 4(a)-4(f) after $\mathrm{Na}_{2} \mathrm{~S}(\mathrm{aq})$ immersion and $\mathrm{H}_{2} \mathrm{O}$ rinsing indicates that excess $\mathrm{As}^{0}$, As oxides, and $\mathrm{Ga}$ oxides all were removed by the $\mathrm{Na}_{2} \mathrm{~S}(\mathrm{aq}) \cdot 9 \mathrm{H}_{2} \mathrm{O}(\mathrm{aq})$ solutions. This is consistent with prior studies of the behavior of GaAs surfaces immersed into 1.0-M KOH-0.8- $\mathrm{M} \mathrm{K}_{2} \mathrm{Se}-0.1-\mathrm{M} \mathrm{K}_{2} \mathrm{Se}_{2}$ solutions, and is expected based on the bulk solubility behavior of As oxides in basic aqueous solutions ${ }^{42}$ and of elemental As in basic aqueous chalcogenide solutions. ${ }^{2,24}$ These spectra are clearly consistent with observations in Sec. A that the 1.0$\mathrm{M} \mathrm{Na}{ }_{2} \mathrm{~S} \cdot 9 \mathrm{H}_{2} \mathrm{O}$ (aq)-induced increase in steady-state $\mathrm{PL}$ intensity was not sensitive to the $\mathrm{GaAs}$ etching procedure.

Figure 5 shows fits to the XPS spectra obtained after the various etching and $1.0-\mathrm{M} \mathrm{Na} \mathrm{Na}_{2} \mathrm{~S} \cdot 9 \mathrm{H}_{2} \mathrm{O}$ (aq) immersion steps. An As-S species was detectable on all of the GaAs samples exposed to $1.0-\mathrm{M} \mathrm{Na} \mathrm{Na}_{2} \mathrm{~S} \cdot 9 \mathrm{H}_{2} \mathrm{O}(\mathrm{aq})$, as evidenced by the presence of peaks at $43.3( \pm 0.2) \mathrm{eV}$ in the As $3 d$ 
region and at $1324.1( \pm 0.3) \mathrm{eV}$ in the As $2 p$ region. Although the As-S peak was more clearly evident in the surface-sensitive As $2 p$ spectral region [Figs. 4(d) -4 (f) vs Figs. 4(a) -4 (c), fitting of the As $3 d$ lineshape confirmed the presence of the As-S phase [Figs. 5(b), 5(d); this peak could not be satisfactorily fit using only the known $\mathrm{As}_{\mathrm{GaAs}}$, $\mathrm{As}^{0}$, and $\mathrm{As}_{2} \mathrm{O}_{3}$ peak energies and linewidths. The calculated coverage of the $\mathrm{As}_{x} \mathrm{~S}_{y}$ phase from the As $2 p$ region was about 2-4-fold higher than the coverage obtained from the As $3 d$ region, indicating inhomogeneity in the film. The As-S peak position was slightly lower in binding energy than the As $3 d$ value of $43.9 \mathrm{eV}$ and much lower than the As $2 p$ value of $1325.7 \mathrm{eV}$ from an authentic $\mathrm{As}_{2} \mathrm{~S}_{3}$ sample on the same XPS instrument, ${ }^{43}$ but is consistent with an As-S phase, most likely of As/S ratio somewhat higher than the value of 0.66 characteristic of $\mathrm{As}_{2} \mathrm{~S}_{3}$.

The presence of sulfur on GaAs exposed to 1.0-M $\mathrm{Na}_{2} \mathrm{~S} \cdot 9 \mathrm{H}_{2} \mathrm{O}(\mathrm{aq})$ was independently verified by collecting XPS data on an instrument equipped with a $\mathrm{Mg}$ anode. This allowed simultaneous investigation of the $\mathrm{S} 2 s, \mathrm{Ga} 3 d$, and As $3 d$ regions by removing the interference between the $\mathbf{S} 2 s$ line and the As Auger signal. The lower resolution of this instrument produced a broad S $2 s$ peak, but the signal for a GaAs sample (exposed to either etch $\mathrm{A}$ or etch B) was centered at $226 \mathrm{eV}$, which is consistent with expectations for the $\mathrm{S}^{2-}$-oxidation state. ${ }^{44}$ The sulfur coverages were fairly independent of the type of etch (Table III), even though the coverage of As-S species did vary for these same GaAs specimens. This change in the total S/As-S ratio was outside of the error of the XPS instrumentation, and indicated that not all of the adsorbed sulfur participated in strong As-S bonding on the GaAs surface.

For all GaAs samples that had been treated with 1.0$\mathrm{M} \mathrm{Na} \mathrm{N}_{2} \mathrm{~S} \cdot 9 \mathrm{H}_{2} \mathrm{O}$ (aq) and thoroughly rinsed with $\mathrm{H}_{2} \mathrm{O}$, the $\mathrm{Ga} 3 d$ lineshape for the lattice $\mathrm{Ga}_{\mathrm{GaAs}}$ was unperturbed relative to that from the near-stoichiometric surface of etch A. This is a qualitative indication that large amounts (> monolayer coverage) of a Ga-S species were not present after the $\mathrm{Na}_{2} \mathrm{~S}$ immersion and $\mathrm{H}_{2} \mathrm{O}$ rinse. However, the chemical shift expected for $\mathrm{Ga}_{2} \mathrm{~S}_{3}$ or related $\mathrm{Ga}$ sulfides is sufficiently close to that of lattice $\mathrm{Ga}_{\mathrm{GaAs}}$ that no quantitative limits on the coverage of this species at submonolayer levels were possible with our XPS instrumentation. ${ }^{45}$ Specifically, the low levels of Ga-S observed by Spindt et al. (using a synchrotron source) on $\mathrm{NH}_{4} \mathrm{~S}$-treated GaAs samples would not have been readily observable using our instrumentation.

b. GaAs surface composition after exposure to 1.0-M $\mathrm{Na}_{2} \mathrm{~S} \cdot 9 \mathrm{H}_{2} \mathrm{O}(\mathrm{aq})$ : Depth profiling with controlled $\mathrm{H}_{2} \mathrm{O}(\mathrm{l})$ exposure. To investigate the depth profile of the overlayer obtained after exposure of GaAs = to 1.0-M $\mathrm{Na}_{2} \mathrm{~S} \cdot 9 \mathrm{H}_{2} \mathrm{O}(\mathrm{aq})$, a series of XP spectra were taken on a sample of low-doped GaAs that had been etched and then exposed to $1.0-\mathrm{M} \mathrm{Na} \mathrm{Na}_{2} \mathrm{~S} \cdot 9 \mathrm{H}_{2} \mathrm{O}(\mathrm{aq})$. The samples were profiled by exposure of the film to single droplets of water while the GaAs was spinning on a spin coater. This procedure was very similar to methods described previously for the wet chemical depth profiling of oxide films on $\mathrm{Si}$ and GaAs. ${ }^{19,30}$
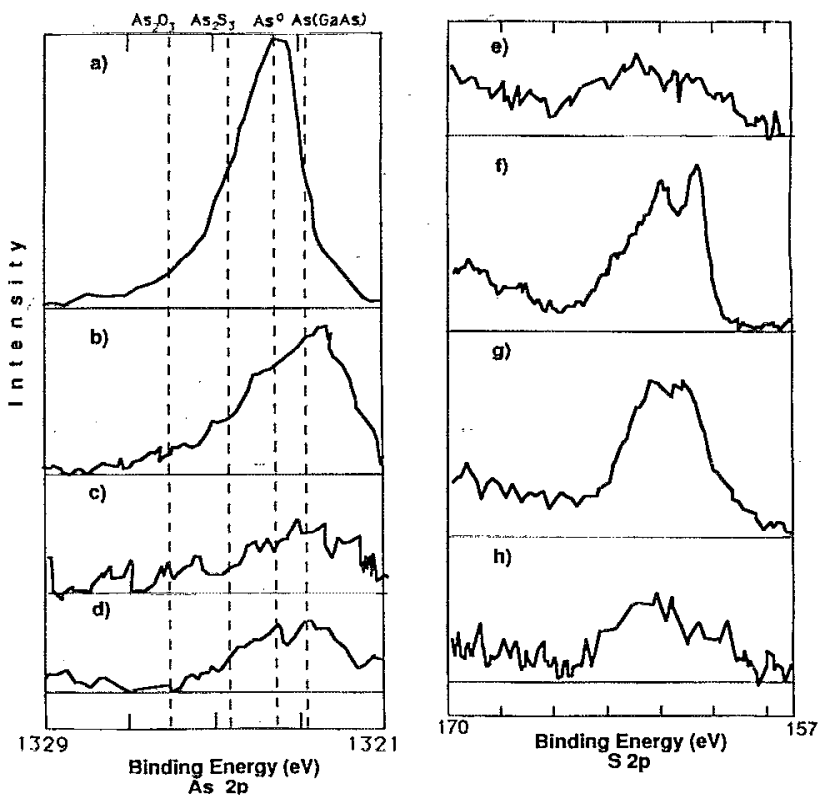

FIG. 6. As $2 p$ and S $2 p$ XP spectra for a sample of boron-compensated, low-doped, (100) $n$-GaAs. The sample was etched with etch $\mathrm{B}$, treated with 1.0-M Na $2 \mathrm{~S} \cdot 9 \mathrm{H}_{2} \mathrm{O}\left(\mathrm{aq}\right.$ ) for $10 \mathrm{~min}$, then gradually rinsed with $\mathrm{H}_{2} \mathrm{O}$. (a) As $3 d$ region after initial etch. (b) As $3 d$ region after sulfide treatment and one drop of $\mathrm{H}_{2} \mathrm{O}$. (c) As $3 d$ region after one more drop of $\mathrm{H}_{2} \mathrm{O}$. (d) As $3 d$ region after final, extensive rinse with $\mathrm{H}_{2} \mathrm{O}$. (e) $\mathrm{S} 2 p$ region of sample after initial etch; same experiment that yielded the As $3 d$ region in (a). (f) $\mathrm{S} 2 p$ region after $\mathrm{Na}_{2} \mathrm{~S}$ film was dried on the surface. (g) $\mathrm{S} 2 p$ region after one drop of $\mathrm{H}_{2} \mathrm{O}$; same experiment that yielded the As $3 d$ region in (b). (h) $\mathrm{S} 2 p$ region after two drops of $\mathrm{H}_{2} \mathrm{O}$; same experiment that yielded the As $3 d$ region in (c). No further changes in the $\mathrm{S} 2 p$ region were observed with rinsing because the signal was already at its baseline value due to the presence of the As Auger line; therefore no $S 2 p$ region was collected for the extensively rinsed sample of (d).

For a GaAs sample that had been exposed to etch $\mathrm{B}$ and then to $1.0-\mathrm{M} \mathrm{Na} 2 \mathrm{~S} \cdot 9 \mathrm{H}_{2} \mathrm{O}(\mathrm{aq})$, XP spectra obtained after various stages of the rinse-spin profiling procedure are displayed in Fig. 6. Examination of the film after immersion into 1.0-M Na $2 \mathrm{~S} \cdot 9 \mathrm{H}_{2} \mathrm{O}(\mathrm{aq})$ yielded negligible intensity from any peaks in the $\mathrm{Ga} 3 d$ or As $3 d$ region. At this stage, only $\mathrm{S} 2 p$ signals characteristic of $\mathrm{S}^{2-}$ and partially oxidized sulfur [Fig. 6(f)], and of $\mathrm{Na} 1 s, \mathrm{C} 1 s$, and $\mathrm{O} 1 s$ were seen in the XPS data. When the films were completely rinsed to reveal the GaAs surface, small amounts of $\mathrm{As}^{0}$, but no Ga or As oxides, were detected by XPS [Fig. 6(d)]. XP spectra obtained at intermediate depths were charactcristic of the limiting spectra and showed the etching of $\mathrm{As}^{0}$ by the $\mathrm{Na}_{2} \mathrm{~S} \cdot 9 \mathrm{H}_{2} \mathrm{O}$ film [Figs. $6(\mathrm{~b}), 6(\mathrm{c})$ ], and the reduction of the amount of sulfur to levels which were not detectable above the As Auger background [Figs. $6(\mathrm{~g}), 6(\mathrm{~h})]$. The final surface was As-deficient in the top layer, with respect to the lattice $\mathrm{Ga}_{\mathrm{GaAs}}$ peak. The extended rinsing used to obtain the spectrum of Fig. 6(d) was also used for all of the samples of Figs. 4-5. In some prior work, samples had not been rinsed with $\mathrm{H}_{2} \mathrm{O}$ after immersion into $\mathrm{Na}_{2} \mathrm{~S} \cdot 9 \mathrm{H}_{2} \mathrm{O}(\mathrm{aq})$ solutions ${ }^{7}$; our data indicate that the $\mathrm{Ga}$ or As XP signals obtained from such specimens may not be characteristic of the general behavior of GaAs surfaces after contact with $\mathrm{Na}_{2} \mathrm{~S} \cdot 9 \mathrm{H}_{2} \mathrm{O}(\mathrm{aq})$ solutions. 
c. Surface composition changes after exposure to $\mathrm{Na}_{2} \mathrm{~S} \cdot 9 \mathrm{H}_{2} \mathrm{O}(\mathrm{aq})$; Variation in $\mathrm{pH}$. The effect of solution $\mathrm{pH}$ was investigated for the $A s^{0}$-rich surface (etch $B$ ), because the $p \mathrm{H}$ may be an important factor in the removal of $\mathrm{As}^{0}$ and in the related improvement in PL intensity. The excess $\mathrm{As}^{0}$ signal intensity produced by etch B was reduced substantially after immersion of the GaAs specimen into either 1.0-M $\mathrm{Na}_{2} \mathrm{~S} \cdot 9 \mathrm{H}_{2} \mathrm{O}(\mathrm{aq}) \quad(p \mathrm{H}=13) \quad$ or $\quad 1.0-\mathrm{M}$ $\mathrm{Na}_{2} \mathrm{~S} \cdot 9 \mathrm{H}_{2} \mathrm{O}(\mathrm{aq})(\mathrm{aq})(p \mathrm{H}=7)$ solutions (Table III). Immersion into the $p \mathrm{H}=7 \mathrm{Na}_{2} \mathrm{~S} \cdot 9 \mathrm{H}_{2} \mathrm{O}(\mathrm{aq})$ solution resulted in slightly higher levels of sulfur remaining on the GaAs surface, but no other differences in surface composition were apparent in response to the variation of $p \mathrm{H}$.

\section{Exposure of GaAs to thiols and other nucleophiles}

XP spectra were collected for a representative set of thiol reagents that were found to affect the GaAs steadystate photoluminescence intensity. Surfaces were investigated after etching to yield either a stoichiometric surface (etch A) or an As ${ }^{0}$-rich surface (etch B). XPS peak energy and coverage information obtained from these experiments are summarized in Table IV.

The dashed line in Fig. 7(a) displays the XP spectra of a GaAs sample that had been etched to obtain a nearstoichiometric surface (etch A). For comparison, the solid line in Fig. 7(a) displays the spectrum of a nominally identical specimen that was etched in parallel but was exposed to a solution of $1.0-\mathrm{M} 4-\mathrm{Cl}$-thiophenol in $\mathrm{CCl}_{4}$ and rinsed with deaerated methanol before introduction into the XPS chamber. All etching and manipulations of these samples were done in a dry box containing flowing $\mathrm{N}_{2}(\mathrm{~g})$, in order to minimize inadvertent oxide formation. The key feature of these As $3 d$ spectra is that the surface As composition was essentially unchanged by exposure to the thiol solution. No signals ascribable to an As-S species were detected, despite the fact that exposure to this thiol yielded a large increase in both the steady-state PL intensity and in the time resolved PL lifetime (vide supra) of GaAs epilayer samples. The thiol was clearly adsorbed onto the GaAs surface, because the $\mathrm{Cl} 2 p$ intensity was significantly above background levels.

To further investigate the potential reactivity of surface $\mathrm{As}^{0}$, another set of $\mathrm{GaAs}$ samples was exposed to the As ${ }^{0}$-rich etch (etch B) and then to 1.0-M 4-Cl-thiophenol in $\mathrm{CCl}_{4}$. The As XPS data for these samples, displayed in Figs. 7(b) and 7(c), showed that excess As ${ }^{0}$ introduced by the etching process was not removed by immersion into the thiol solution. Also, no As-sulfide peaks were detectable on this surface. This can be seen more clearly from the spectral fits to the As $2 p$ region that are displayed in Fig. 8. Although there was a peak at higher binding energy, this peak was also present in the etched sample [Fig. 8(a)] and is mostly likely due to an As suboxide. Any As-S signal was certainly minor compared to the levels detected after exposure to 1.0-M Na $2 \mathrm{~S} \cdot 9 \mathrm{H}_{2} \mathrm{O}(\mathrm{aq})$, as shown in Figs. 5(f) $-5(\mathrm{~h})$. This lack of a detectable As-S phase was found to be representative of both the thiols investigated by XPS (1,2-dithiolethane and 4-Cl-thiophenol) on $\mathrm{As}^{0}$-rich GaAs surfaces (Table IV).
To insure that the $\mathrm{Cl}$ signals in the wide scan using the Al x-ray source instrument were indicative of the persistent adsorption of the 4-Cl-thiophenol, XPS data were also collected with the $\mathrm{Mg}$ x-ray source. For GaAs samples exposed to either the stoichiometric or As ${ }^{0}$-rich etches (etch $\mathrm{A}$ or $\mathrm{B}$ ) and then exposed to 1.0-M 4-Cl-thiophenol in $\mathrm{CCl}_{4}$, a Cl:S elemental ratio of $(1.1 \pm 0.2)$, and a lack of $\mathrm{Ga}-\mathrm{Cl}$ or As-Cl peaks, was observed (Table IV). This implies that the $\mathrm{Cl}$ intensity obtained on the high-energy resolution $\mathrm{Al}$ x-ray photoelectron spectrometer was a reliable indication of the adsorbed 4-Cl-thiophenol coverage, and that the lack of As-S formation in these samples was not due to a lack of reactivity of these surfaces with the thiol.

An additional set of experiments was done to determine if there was any photochemical formation of an As-S phase under laser irradiation, since some time dependence of steady-state PL intensity was occasionally observed. A sample of the $1.0-\mu \mathrm{m}$-thick GaAs epilayer was etched to remove the top $\mathrm{AlGaAs}$ layer, exposed to etch $\mathrm{A}$ in a glove box containing flowing $\mathrm{N}_{2}(\mathrm{~g})$, sealed in a glass cell, and subjected to XPS analysis. XPS data collected on this sample revealed a spectrum identical to that displayed in Fig. 7 (a). The sample was then returned to the glove box, soaked in a 1.0-M 4-Cl-thiophenol solution as described above, sealed again in a glass cell and irradiated for $20 \mathrm{~min}$. XPS obtained after this process showed no change in the GaAs surface composition except for the detection of the anticipated small amount of $\mathrm{Cl}$ from the adsorbed thiol.

XP spectra were also collected for GaAs surfaces that had been exposed to two other organic reagents. For a sample of GaAs that had been etched to yield an As $^{0}$-rich surface (etch B) and then exposed to 3-methylthiophene (liquid), XPS data showed no change in the surface As or Ga regions and no detectable sulfur in the $\mathrm{S} 2 p$ region. 3-methylthiophene did not produce significant increases in the steady-state PL intensity of GaAs surfaces; the XPS data imply that this is simply due to an extremely weak, or readily reversible, interaction between the thiophene and the GaAs surface.

It was also of interest to examine the surface composition of a GaAs sample that had been exposed to sodium methoxide, because this reagent yielded a large increase in the steady-state PL intensity without a concomitant increase in the high-level injection PL decay time. Figure 9 depicts the XP spectrum that was obtained for a GaAs surface that had been treated with etch $B$, and also displays the XP spectrum for a similar sample that had been exposed to 1.0-M NaOCH 3 in $\mathrm{CH}_{3} \mathrm{OH}$. Although the elemental $\mathrm{As}^{\mathrm{O}}$ coverage was reduced slightly by exposure to 1.0-M NaOCH 3 , most of the $\mathrm{As}^{0}\left(2 \times 10^{-9} \mathrm{~mol} \mathrm{~cm}^{-2}\right)$ remained on the GaAs surface. The lack of gross stoichiometry changes, or the appearance of new chemical species after $\mathrm{OCH}_{3}^{-}$exposure, implies that the resulting small changes in surface stoichiometry effected by this reagent were not detectable with the sensitivity levels of our XPS analysis. 


\begin{tabular}{|c|c|c|c|c|c|c|c|c|c|c|c|c|c|c|c|c|c|c|c|}
\hline \multirow[b]{2}{*}{ Sample } & \multirow[b]{2}{*}{$\begin{array}{l}x \text {-ray } \\
\text { source }\end{array}$} & \multicolumn{3}{|c|}{ Ga $3 d$} & \multicolumn{7}{|c|}{ As $3 d$} & \multicolumn{4}{|c|}{ As $2 p$} & \multirow[t]{2}{*}{$\begin{array}{c}\mathrm{Ga} / \mathrm{As} \\
3 d \\
\text { region }^{\mathrm{b}}\end{array}$} & & $\mathrm{S} 2 s$ & \multirow[t]{2}{*}{$\begin{array}{c}\mathrm{C} 1 \mathrm{~s} \\
\mathrm{eV}\end{array}$} \\
\hline & & $\begin{array}{c}\mathrm{Ga} \\
(\mathrm{GaAs}) \\
\mathrm{eV}\end{array}$ & $\begin{array}{c}\mathrm{Ga} \\
\left(\mathrm{Ga}_{2} \mathrm{O}_{3}\right) \\
\mathrm{eV}\end{array}$ & $\begin{array}{c}\Gamma \\
\left(\mathrm{Ga}_{2} \mathrm{O}_{3}\right) \\
\mathrm{mol} / \mathrm{cm}^{2} \\
\times 10^{9}\end{array}$ & $\begin{array}{c}\text { As } \\
\text { (GaAs) } \\
\mathrm{eV}\end{array}$ & $\begin{array}{c}\mathrm{As} \\
\left(\mathrm{As}_{2} \mathrm{O}_{3}\right) \\
\mathrm{eV}\end{array}$ & $\begin{array}{c}\Gamma \\
\left(\mathrm{As}_{2} \mathrm{O}_{3}\right) \\
\mathrm{mol} / \mathrm{cm}^{2} \\
\times 10^{9}\end{array}$ & $\begin{array}{c}\text { As } \\
\left(A s^{0}\right) \\
e V\end{array}$ & $\begin{array}{c}\Gamma \\
\left(\mathrm{As}^{0}\right) \\
\mathrm{mol} / \mathrm{cm}^{2} \\
\times 10^{9}\end{array}$ & $\begin{array}{c}A s \\
\left(A s_{x} S_{y}\right) \\
e V\end{array}$ & $\begin{array}{c}\Gamma \\
\left(\mathrm{As}_{x} \mathrm{~S}_{y}\right) \\
\mathrm{mol} / \mathrm{cm}^{2} \\
\times 10^{9}\end{array}$ & $\begin{array}{c}\text { As } \\
\text { (GaAs) } \\
\text { eV }\end{array}$ & $\begin{array}{c}\mathrm{As} \\
\left(\mathrm{As}_{2} \mathrm{O}_{3}\right) \\
\mathrm{eV}\end{array}$ & $\begin{array}{c}\text { As } \\
\left(\mathrm{As}^{(B)}\right) \\
\mathrm{eV}\end{array}$ & $\begin{array}{c}\mathrm{As} \\
\left(\mathrm{As}_{x} \mathrm{~S}_{y}\right) \\
\mathrm{eV}\end{array}$ & & $\mathrm{eV}$ & $\begin{array}{c}\Gamma \\
(\mathrm{S}) \\
\mathrm{mol} / \mathrm{cm}^{2} \\
\times 10^{9}\end{array}$ & \\
\hline Etch $A^{c}$ & $\mathrm{Al}$ & 19.2 & 20.0 & 0.4 & 41.0 & $\cdots$ & 0.0 & 41.7 & 0.8 & $\cdots$ & 0.0 & & & & & 1.7 & & & 285.3 \\
\hline$+1.0-\mathrm{M} 4-\mathrm{Cl}-\mathrm{C}_{6} \mathrm{H}_{4}-\mathrm{SH}$ in $\mathrm{CCl}_{4}(30 \mathrm{~min})$ & $\mathrm{Al}$ & 19.2 & 20.1 & 0.5 & 41.1 & $\cdots$ & 0.0 & 41.8 & 0.8 & $\cdots$ & 0.0 & & & & & 1.1 & & $\mathrm{~d}$ & 285.2 \\
\hline$+1.0-\mathrm{M} 4-\mathrm{Cl}-\mathrm{C}_{6} \mathrm{H}_{4}-\mathrm{SH}$ in $\mathrm{CCl}_{4}(30 \mathrm{~min})$ & $\mathbf{M g}$ & 20.0 & 20.9 & 0.2 & 42.0 & $\cdots$ & 0.0 & $\cdots$ & 0.0 & $\cdots$ & 0.0 & & & & & 1.0 & 227.6 & 0.4 & 285.1 \\
\hline$+1.0-\mathrm{M} 4 \mathrm{Cl}-\mathrm{C}_{6} \mathrm{H}_{4}-\mathrm{SH}+1.0-\mathrm{M} \mathrm{NaOCH}$ & $\mathrm{Al}$ & 18.8 & 19.8 & 0.6 & 40.7 & 44.4 & 0.4 & $\cdots$ & 0.0 & $\cdots$ & 0.0 & & & & & 1.1 & & & 285.6 \\
\hline in methanol $(30 \mathrm{~min})$ & $\mathbf{M g}$ & & & & 41.3 & $\cdots$ & 0.0 & $\cdots$ & 0.0 & $\cdots$ & 0.0 & & & & & $\cdots$ & 227.0 & 0.4 & 286.6 \\
\hline Etch B & Al & 19.7 & 20.6 & 0.4 & 41.6 & 44.4 & 0.4 & 42.3 & 2.7 & & & 1323.3 & 1325.6 & 1324.1 & $\cdots$ & 1.5 & & & 284.7 \\
\hline$+1.0-\mathrm{M} 4-\mathrm{Cl}^{-} \mathrm{C}_{6} \mathrm{H}_{4}-\mathrm{SH}$ in $\mathrm{CCl}_{4}(30 \mathrm{~min})$ & $\mathrm{Al}$ & 19.4 & $\cdots$ & 0.0 & 41.2 & $\cdots$ & 0.0 & 42.0 & 4.9 & $\cdots$ & 0.0 & 1323.0 & 1325.2 & 1323.9 & $\cdots$ & 1.6 & & e & 285.1 \\
\hline$+\mathrm{HS}^{-\mathrm{CH}_{2}} \mathrm{CH}_{2}$-SH (liquid) $(1 \mathrm{~h})$ & Al & 19.0 & 20.2 & 0.2 & 40.8 & $\cdots$ & 0.0 & 41.6 & 3,0 & $\cdots$ & 0.0 & & & & & 0.8 & & & 285.5 \\
\hline$+1-\mathrm{M} \mathrm{NaOCH}_{3}$ in methanol $(30 \mathrm{~min})$ & $\mathrm{Al}$ & 19.2 & $\cdots$ & 0.0 & 41.0 & $\cdots$ & 0.0 & 41.8 & 1.9 & $\cdots$ & 0.0 & 1322.8 & $\cdots$ & 1323.8 & $\cdots$ & 1.9 & & & 285.3 \\
\hline
\end{tabular}

${ }^{\mathrm{A}} \mathrm{Al}=$ Data taken with monochromatic AlK $\alpha \mathrm{x}$ rays $(1486.6 \mathrm{eV})$ on a Surface Science Instruments Model 100.

$\mathrm{Mg}=$ Data taken with $\mathrm{Mg} K \alpha \mathrm{x}$ rays $(1254 \mathrm{eV})$ on a VG Mark II.

All coverages were calculated relative to the As $3 d$ GaAs substrate peak. A value of 0.0 indicates that the level was less than $0.1 \times 10^{-9}$ mol/ $\mathrm{cm}^{2}$.

"..." indicates that the peaks were undetectable due to either sensitivity or resolution.

"The $\mathrm{Ga} / \mathrm{As}$ ratio' is based on substrate peaks and does not include oxides.

${ }^{c} \mathrm{Etch} \mathrm{A}=1.0-\mathrm{M} \mathrm{KOH}(15 \mathrm{~s}), 0.05 \% \mathrm{Br}_{2} /$ Methanol $(15 \mathrm{~s})$, repeated three times and ending in $\mathrm{KOH}$.

Etch $B=$ Etch $\mathrm{A}+30$ s $1: 1: 100\left(\mathrm{H}_{2} \mathrm{SO}_{4}: 30 \% \mathrm{H}_{2} \mathrm{O}_{2}: \mathrm{H}_{2} \mathrm{O}\right)$.

${ }^{\mathrm{d}}$ The coverage of thiol based on the $\mathrm{Cl} 2 p$ region is $0.9 \times 10^{-9} \mathrm{~mol} / \mathrm{cm}^{2}$

The coverage of thiol based on the Cl $2 p$ region is $1.7 \times 10^{-9} \mathrm{~mol} / \mathrm{cm}^{2}$. 

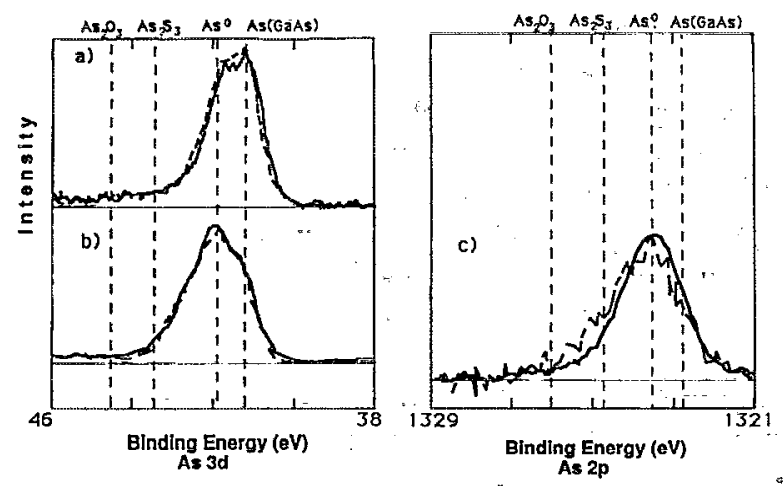

FIG. 7. As $3 d$ and $2 p$ XP spectra for bulk $10^{17}$-doped (100) $n$-GaAs samples, taken with monochromatic $\mathrm{Al} x$ rays. The dashed lines are spectra for freshly etched samples, and solid lines are spectra obtained for a separate set of samples that had been etched and then immersed into 1.0$\mathrm{M}$ 4-chlorothiophenol in $\mathrm{CCl}_{4}$ for $30 \mathrm{~min}$, followed by rinsing with methanol. (a) As $3 d$ regions after etch A, and after exposure to the thiol. (b) As $3 d$ regions after exposure to etch $B$, and after exposure to the thiol. (c) As $2 p$ regions corresponding to the sample of (b).

\section{DISCUSSION}

\section{A. Photoluminescence measurements}

This work has shown that a series of chemical reagents can be utilized to substantially reduce recombination rates at GaAs surfaces. The resulting reductions in low-level injection surface recombination velocity were quite large, and sulfur containing molecules produced passivation effects that were apparent under both high- and low-level injection conditions. This implies that a significant contribution to the passivation process was a reduction in the surface trap density and/or trapping cross section. A second type of molecule (methoxide) showed a reduction in steady-state surface recombination velocity in the low injection, steady-state experiments. The methoxide ion did not show an increase in lifetime in the high injection PL

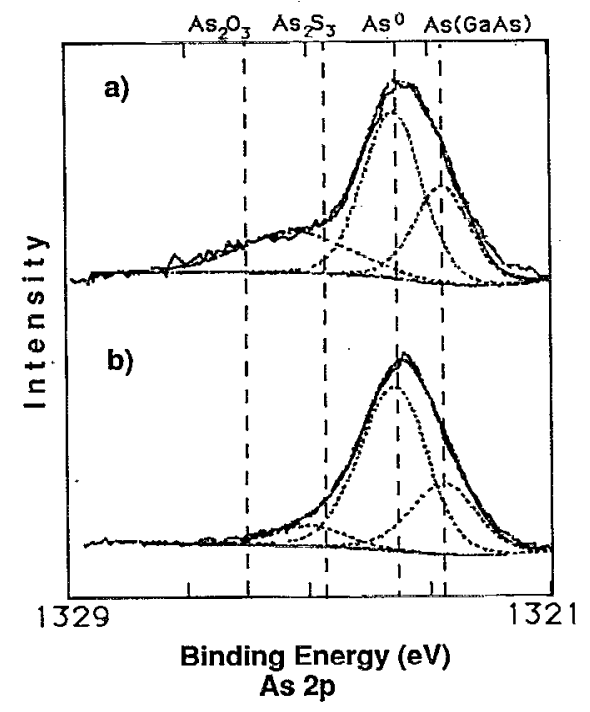

FIG. 8. Peak fits for the As $2 p$ XP spectra of Fig. 7(c). (a) Spectrum and fits after etch B. (b) Spectrum and fits after etching and exposure to the thiol solution.
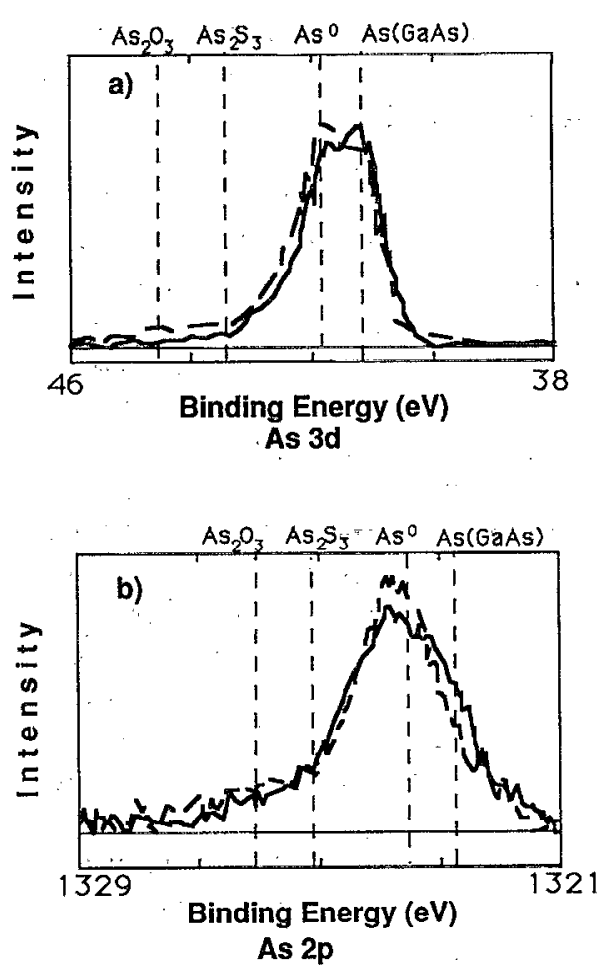

FIG. 9. (a) As $3 d$ and (b) As $2 p$ XP spectra for bulk $10^{17}$-doped (100) $n$-GaAs taken with monochromatic $\mathrm{Al}$ x-rays. The dashed lines are the spectra obtained after exposure to etch $B$, while the solid lines represent the XPS data ubtained after immersion of the GaAs into $1.0-\mathrm{M}$ sodium methoxide for $30 \mathrm{~min}$, followed by extensive rinsing with methanol.

experiments, thus indicating a second mechanism whereby the steady-state PL yield increases through a shift in the surface Fermi level.

In general, the increase in steady-state PL intensity followed the trend in donor atom of $\mathrm{S}>\mathrm{O}$. This is characteristic of a so-called "class b," or soft acid center, ${ }^{37}$ as opposed to the behavior expected for the prototypical hard acid center of a proton. Arsenic sites would be expected to exhibit such chemical behavior, although Ga defects in a polarizable environment such as GaAs might also exhibit similar reactivity. It is unlikely, however, that oxides or hydroxides on the GaAs surface would show this order of binding or reactivity, so the PL observations suggest that these species are not the electrically important surface sites. The trends in reactivity certainly suggest that an electron deficient site is present on the GaAs surface, and that this species is the key chemical site for recombination. Although this trend in reactivity is unfortunately not sufficient to identify unambiguously the chemical nature of the recombination sites, it should provide a useful guideline for choosing other potential surface passivating reagents on GaAs surfaces. A more quantitative analysis of the trends in surface ligation, specifically to address why the thiolates did not exhibit PL increases that generally were superior to those obtained with the thiols, would require determination of the binding constants and saturation coverages of the various ligands; however, the reduced magnitude of the PL effect on rinsed GaAs samples precludes the use of 
vacuum spectroscopic methods for this purpose. Equilibrium isotherm measurements ${ }^{46}$ would be required to achieve these measurements, and these results will be the topic of a separate experimental study.

The general reactivity of donors with the GaAs surface is similar in many respects to recent observations on other semiconductor surfaces. McLendon et al ${ }^{47}$ have observed that exposure to ethylenediaminetetraacetate yields a dramatic effect on the surface recombination properties of $\mathrm{Cd}$ rich CdSe colloids, presumably through chelation of the Cd surface trap sites. Similar electron donor effects have also been observed by Ellis and co-workers in studies of the low level PL intensity of CdSe surfaces, ${ }^{48}$ where exposure to strong nitrogen and oxygen donors and/or chelating reagents have been observed to produce large increases in the steady-state PL signal. These workers have proposed that the origin of this steady-state PL change arises from a modification of the equilibrium surface Fermi level position (i.e., a change in the so-called "dead layer" width) upon adsorption of the amine reagents, although the passivation of trap recombination cannot be explicitly ruled out without direct information on either the surface recombination velocity under high injection or on the absolute value of the equilibrium surface Fermi level position. Our results indicate that both mechanisms are relevant to the GaAs surface chemistry; species such as methoxide do not effect changes in the surface recombination velocity under high injection, but thiols and $\mathrm{HS}^{-}$(aq) solutions do yield substantial reductions in the inherent surface recombination rates.

In our work, the real-time PL data clearly indicated that the methoxide treatment improved the steady-state PL intensity primarily through a change (increase) in the equilibrium band bending, without a significant reduction in the inherent surface state recombination rate. The high level injection PL data of Fig. 3 also confirmed that the $\mathrm{Na}_{2} \mathrm{~S}(\mathrm{aq})$ and 4-Cl-thiophenol treatments significantly affected the surface recombination properties. This conclusion is supported by previous high level injection if decay signals obtained for GaAs surfaces exposed to 1.0-M $\mathrm{Na}_{2} \mathrm{~S} \cdot 9 \mathrm{H}_{2} \mathrm{O}(\mathrm{aq})$, but does not support the hypothesis of Spindt et $a l^{8,15}$ that increased band bending is the primary cause of the steady-state PL improvement. In fact, increased band bending should increase the dead layer width, ${ }^{48}$ which should produce a decrease in the steadystate luminescence intensity due to enhanced charge separation. This effect would only be opposed by a band-bending induced reduction in effective surface recombination velocity for certain specific conditions of the surface Fermilevel position and of the (majority-carrier/minoritycarrier) capture cross-section ratio for the important trap sites. ${ }^{16}$ Thus, explanations invoking increased band bending as the source of the PL effect are inconsistent with the experimental behavior of the GaAs/sulfide system and with general expectations based on conventional carrier trapping statistics at depleted, uninverted, semiconductor interfaces.

Although both types of reagents $\left(\mathrm{OCH}_{3}^{-}\right.$and thiols) produce a change in the observed low level steady-state PL intensity, the coordination of GaAs surface traps is the desired target of our work because of its more general relevance to the reduction of surface recombination processes in a variety of device configurations and under a variety of carrier injection levels. Future work targeting reagents with the chemical properties of sulfides (electron donating, but polarizable), but having greater stability in air may result in even better passivants.

\section{B. Surface compositional changes as monitored by X-ray photoelectron spectroscopy}

A key result of the XPS studies reported herein is that, in certain cases, substantial $\mathrm{As}^{0}$ remained on the GaAs surface even when the surface recombination velocity was significantly lower than that of the etched, air-exposed $\mathrm{GaAs}$ surface. Although the basic $1.0-\mathrm{M} \mathrm{Na} 2 \mathrm{~S} \cdot 9 \mathrm{H}_{2} \mathrm{O}$ (aq) solutions were found to be effective in removing excess $\mathrm{As}^{0}$, exposure to thiols in nonaqueous solvents did not substantially reduce the $\mathrm{As}^{0}$ content of the GaAs surface. 4-Clthiophenol did, however, yield substantial reductions in both the low-level and high-level surface recombination velocity. Furthermore, no $\mathrm{As}_{x} \mathrm{~S}_{y}$ signal was evident after exposure of GaAs surfaces to the nonaqueous thiol solutions, indicating that the formation of an epitaxial overlayer of $\mathrm{As}_{2} \mathrm{~S}_{3}$ from excess $\mathrm{As}^{0}$ is not the key chemical process responsible for lowering surface recombination in these systems.

Another significant observation is that only submonolayer (about one half to three quarters of a monolayer) levels of As sulfides were observed in this work after exposure either to $\mathrm{Na}_{2} \mathrm{~S} \cdot 9 \mathrm{H}_{2} \mathrm{O}(\mathrm{aq}$ ) solutions or to $\mathrm{NaHS}(\mathrm{aq})$ solutions. These low $A s_{x} S_{y}$ signals are in qualitative accord with the results of Tiedje et al., ${ }^{9}$ but the $\mathrm{As}_{x} \mathrm{~S}_{y}$ peak intensities and calculated $\mathrm{As}_{x} \mathrm{~S}_{y}$ coverages are substantially lower than those reported in the work of Sandroff and co-workers. ${ }^{12}$ Sandroff and co-workers observed a slightly higher binding energy $A s_{x} S_{y}$ phase after treatment with $\mathrm{Na}_{2} \mathrm{~S}$ than after treatment with $\mathrm{NH}_{4} \mathrm{~S}^{12}$ One possible explanation for the difference in the As $2 p$ XP spectra is that in the Sandroff study the $\mathrm{Na}_{2} \mathrm{~S}$ films were rinsed with $\mathrm{CS}_{2}$ so that the surface was visible by XPS. NaOH, which is a component of a dried $\mathrm{Na}_{2} \mathrm{~S}$ film, reacts with $\mathrm{CS}_{2}$ to form $\mathrm{NaCS}_{3}{ }^{49}$ This compound could further react with any arsenic sulfide that was present on the surface to form an arsenic polysulfide. In our study and the study by Tiedje, water was used to rinse the film before XPS investigation. Also, our study has shown that the large amount of oxide present in some prior studies ${ }^{7,11,12}$ is a result of handling procedures and is not inherent in the chemistry of the surface.

The magnitude of the steady-state PL intensity change observed in this work is in accord with prior observation on epilayer-type GaAs samples. Taken together with our XPS measurements, this set of observations indicates that the PL changes resulting from emersed and dried GaAs surfaces do not correlate with the $\mathrm{As}_{x} \mathrm{~S}_{y}$ coverages determined on thoroughly rinsed GaAs samples exposed to thiols and aqueous sulfides. This conclusion was verified in this work for GaAs samples that were handled under a 
variety of conditions, including aerobic versus anaerobic etching and sulfide treatment, exposure to partially oxidized or totally reduced sulfide solutions, and exposure to $\mathrm{Na}_{2} \mathrm{~S}(\mathrm{aq})$ following establishment of a variety of different GaAs surface stoichiometries.

The similarity of the final GaAs surface stoichiometry after exposure to aqueous sulfides, despite the substantial differences in the three initial GaAs surface compositions induced by the various etching procedures, is also of interest with respect to the surface passivation effect. This behavior can be readily understood by reference to the solubility properties of $\mathrm{Ga}$ oxides, As oxides, and elemental As, and by reference to prior experimental investigations of GaAs surface reactivity after contact with basic aqueous chalcogenide solutions. ${ }^{23,50}$ Specifically, after immersion into a $1.0-\mathrm{M} \mathrm{KOH}-0.80-\mathrm{M} \mathrm{K}_{2} \mathrm{Se}$ (aq)-0.1- $\mathrm{M} \mathrm{K}_{2} \mathrm{Se}_{2}$ (aq) solution, a remarkably clean, near stoichiometric, GaAs surface was produced regardless of the initial GaAs etching procedure. ${ }^{23}$ Although the prior work specifically dealt with reactions of $\mathrm{GaAs}$ in contact with $\mathrm{KOH}-\mathrm{K}_{2} \mathrm{Se}(\mathrm{aq})$ solutions, the observations of $\mathrm{GaAs} / \mathrm{NaOH}-\mathrm{Na}_{2} \mathrm{~S}$ (aq) surface chemistry reported herein (Table III, Fig. 4) are fully consistent with these earlier XPS observations.

This surface chemistry of oxidized As also naturally provides a mechanism for the formation of the $\mathrm{As}_{2} \mathrm{~S}_{3}$ that has been observed in this work and in prior studies of the $\mathrm{GaAs} / \mathrm{Na}_{2} \mathrm{~S}(\mathrm{aq})$ chemistry., ${ }^{4,7-12}$ Oxidized As [i.e., As(III)] and oxidized $\mathrm{Ga}$ [Ga (III)] readily react with aqueous sulfide solutions to yield $\mathrm{As}_{2} \mathrm{~S}_{3}$ and $\mathrm{Ga}_{2} \mathrm{~S}_{3}$, ${ }^{51(\mathrm{a})}$ thus, oxidized GaAs surfaces are expected to produce $\mathrm{As}_{2} \mathrm{~S}_{3}$ and $\mathrm{Ga}_{2} \mathrm{~S}_{3}$ without the concomitant formation of covalent bonds to the substrate or passivation of surface states. Deposition of the product of a precipitation reaction has been observed previously on GaAs surfaces that have been exposed to basic solutions of Co (II) or Co (III) complexes; this procedure resulted in deposition of multilayer coverages of a $\mathrm{Co}(\mathrm{OH})_{2}$ surface species that persisted on the GaAs surface even after thorough rinsing with $\mathrm{H}_{2} \mathrm{O} .{ }^{50}$ However, unlike $\mathrm{Co}(\mathrm{OH})_{2}, \mathrm{As}_{2} \mathrm{~S}_{3}$ is partially soluble in aqueous basic solutions (due to the formation of soluble thio and oxy anions), ${ }^{51(b)}$ so the observed $\mathrm{As}_{2} \mathrm{~S}_{3}$ coverages on an air-exposed GaAs sample that has been exposed to 1.0-M Na $2 \mathrm{~S}(\mathrm{aq})$ and rinsed with $\mathrm{H}_{2} \mathrm{O}$ are not expected to accurately reflect either the initial $\mathrm{As}_{2} \mathrm{~S}_{3}$ levels or the coverage of sulfur that is covalently bound to the surface. This rather complex surface chemistry may well account for the differences in As-S coverages reported in various studies. ${ }^{9,12}$

Furthermore, on GaAs surfaces without substantial As(III) or $\mathrm{As}^{0}$ present initially, and in fully reduced sulfide solutions, formation of monolayer levels of $\mathrm{As}_{2} \mathrm{~S}_{3}$ from GaAs must result in the formation of reduced products, which would presumably be elemental $\mathrm{Ga}$ and/or $\mathrm{H}_{2}(\mathrm{~g})$. No XPS signals from elemental Ga were observed after $\mathrm{Na}_{2} \mathrm{~S}(\mathrm{aq})$ immersion and $\mathrm{H}_{2} \mathrm{O}$ rinsing, implying coverages of $\mathrm{Ga}^{0}<1 \times 10^{-10} \mathrm{~mol} / \mathrm{cm}^{2}$. Additionally, estimates of the thermodynamics of this reaction $(2 \mathrm{GaAs}+6$ $\mathrm{S}_{2}^{-}+12 \mathrm{H}_{2} \mathrm{O}=\mathrm{As}_{2} \mathrm{~S}_{3}+\mathrm{Ga}_{2} \mathrm{~S}_{3}+12 \mathrm{OH}^{-}+6 \mathrm{H}_{2}$ ) from the appropriate half-cell potentials ${ }^{42}$ indicate that it is un- likely to be exoergic. These arguments, combined with the observation that the PL intensity was independent of the initial etching solution, and with the fact that $\mathrm{As}_{2} \mathrm{~S}_{3}$ formation was not observed from the thiol exposure in nonaqueous solvents, lend support to the notion that bulk $\mathrm{As}_{2} \mathrm{~S}_{3}$ formation is not directly related to passivation of the key chemical trapping species at the GaAs surface.

Similar arguments can be applied to the formation of $\mathrm{Ga}_{2} \mathrm{~S}_{3}$ from oxidized $\mathrm{Ga}$. Spindt et $a l^{6}{ }^{6}$ have suggested that bulk thermodynamics based on heats of formation indicate that $\mathrm{Ga}_{2} \mathrm{~S}_{3}$ should be formed preferentially with respect to $\mathrm{As}_{2} \mathrm{~S}_{3}$, and suggested that this species plays a key role in the $\mathrm{GaAs} / \mathrm{Na}_{2} \mathrm{~S}$ interface passivation chemistry. The above analysis for $\mathrm{As}_{2} \mathrm{~S}_{3}$ formation suggests that an alternative mechanism for $\mathrm{Ga}_{2} \mathrm{~S}_{3}$ formation is the reaction of inadvertently oxidized $\mathrm{Ga}$ with the aqueous sulfide solutions. This implies that unless rigorously anaerobic conditions are maintained throughout the experiment, the detection of $\mathrm{Ga}_{2} \mathrm{~S}_{3}$ on the GaAs surface may not indicate formation of a covalent bond between the $\mathrm{Ga}_{2} \mathrm{~S}_{3}$-type layer and the GaAs itself, and may not correlate with the bonding to the important electrical trap sites. This is consistent with the rather high levels of oxide evident in some earlier XPS work on $\mathrm{Na}_{2} \mathrm{~S}$-treated surfaces, ${ }^{7}$ and suggests that observation of $\mathrm{Ga}_{2} \mathrm{~S}_{3}$ may be unrelated to the chemistry of the important surface trap levels.

We also note, with regards to whether Ga or As sulfide would be the more thermodynamically favorable, that kinetics can frequently dominate in surface reactions. In the case of $\mathrm{Si}$, surface thermodynamics indicate that $\mathrm{Si}-\mathrm{F}$ bonds are much stronger than $\mathrm{Si}-\mathrm{H}$ bonds, ${ }^{52}$ yet observation has shown that kinetic considerations dramatically overshadow the thermodynamic predictions on Si surfaces. Stable Si-H terminated $\mathrm{Si}$ surfaces result from the exposure of oxidized Si to aqueous $48 \%$ HF solutions. ${ }^{53}$ Of course, when heated to high temperatures, equilibrium may be established and the thermodynamically predicted species of $\mathrm{Ga}_{2} \mathrm{~S}_{3}$ should then be observed for the GaAs $/ \mathrm{Na}_{2} \mathrm{~S} \cdot 9 \mathrm{H}_{2} \mathrm{O}$ interface; however, the $\mathrm{Si}$ example serves to illustrate that bond strength arguments must be used with caution to predict surface compositions obtained in the kinetically limited situations commonly encountered when semiconductor surfaces are immersed in aqueous solutions at room temperature.

With respect to the energetics of the GaAs surface, ultraviolet photoelectron spectroscopy (UPS) of $\mathrm{Na}_{2} \mathrm{~S}$-treated $\mathrm{GaAs}$ surfaces has been used to show that the surface Fermi level is still pinned at a value of $0.7-0.9 \mathrm{eV}$ below the bottom of the conduction band edge. ${ }^{7}$ The XPS spectrum obtained in the present work after immersion of $\mathrm{GaAs}$ in $1.0-\mathrm{M} \mathrm{Na} \mathrm{Na}_{2} \mathrm{~S}(\mathrm{aq})$ solutions did not display any signals from the Ga or As substrate lines (Table III), and therefore suggests that independent support for the UPS measurements is needed from another type of experiment. A nonhomogeneous surface coating could yield XPS signals from the uncovered and untreated portion of the GaAs substrate, and this scenario would explain the XPS and UPS spectra reported in previous work on unrinsed samples. ${ }^{7}$ The high coverage of oxidized As in the UPS 
sample reported earlier, combined with the observations above that $\mathrm{Ga}$ oxides and As oxides are readily dissolved by basic $\mathrm{Na}_{2} \mathrm{~S}(\mathrm{aq})$ solutions, strongly suggests that the areas contributing to the observed XPS and UPS signals were not exposed to the $\mathrm{Na}_{2} \mathrm{~S}$ treatment. This is consistent with the extensive literature indicating that oxidized $\mathrm{GaAs}$ surfaces have their surface Fermi levels pinned. $0.7-0.9 \mathrm{eV}$ positive of the conduction band edge. ${ }^{54}$ We note that the $\mathrm{rf}$ conductivity data of Yablonovitch et al. ${ }^{14}$ indicate that the surface Fermi-level position on $\mathrm{Na}_{2} \mathrm{~S}$-coated surfaces depends on the injection level and that it can be unpinned under high level injection conditions. Although the data of Yablonovitch et $a .^{14}$ are not consistent with a strongly pinned surface Fermi level at $0.7-0.9 \mathrm{eV}$ below the conduction band edge, their observations are consistent with the increased PL decay times observed in this work for the $\mathrm{Na}_{2} \mathrm{~S}$ and 4-Cl-thiophenol treatments of epilayer-type GaAs samples and with the analysis of the XPS and UPS data presented above.

In general, it can be seen that the chemistry of GaAs with sulfides is complex and varied. The chemical probes indicate that the important surface recombination site is "soft" and electron deficient in nature, but the sulfide binding constant must be relatively weak because rinsing with solvent substantially diminishes the steady-state GaAs PL, intensity. This fact presents a severe impediment to obtaining useful correlations between the surface chemistry determined with vacuum spectroscopic methods and the reactivity of the actual electrical recombination sites on $\mathrm{Na}_{2} \mathrm{~S} \cdot 9 \mathrm{H}_{2} \mathrm{O}(\mathrm{aq})$-coated $\mathrm{GaAs}$ interfaces. The nonaqueous thiol solutions are better suited to formulate these correlations, but no changes in gross surface stoichiometry have been observed for thiol reagents that yield large improvements in the steady-state PL intensity. Further spectroscopic-based advances in our understanding of the chemistry of the recombination sites will require methods that probe directly the bonding of a limited number of surface sites in the presence of higher coverages of precipitates and other spectator surface species. For these reasons, the use of chemical probes to elucidate the surface state identity seems to be a promising avenue for further research, and such experiments are being pursued further in our laboratory at present.

\section{v. CONCLUSIONS}

This study has several implications for how various complexes interact with GaAs surfaces:

(1) The steady-state PL measurements indicated a correlation between the electron donating ability of a species and the improvement in PL. The improvement in PL with methoxide, phenoxide, and ethylenediamine, and the transistory improvement with hydroxide, indicated that other strong electron donors beside sulfides can exhibit beneficial effects on GaAs surface recombination rates. The increase in PL followed the trend $S>\mathrm{O}$, which is characteristic of a soft acid center. Charge alone was not sufficient to effect an improvement in steady-state PL, as several ionic species did not produce any decrease in the observed surface recombination rate.
(2) The time-resolved PL studies showed that there was an increase in carrier lifetime, in the GaAs flat band condition, after treatment with 4-Cl-thiophenol or with aqueous sulfides. Therefore, these surface treatments decreased the cross section or density of the important surface traps. Other reagents, such as sodium methoxide, yielded substantial increases in the stcady-state PL intensity, but did not affect the inherent GaAs surface carrier trapping rates. GaAs surfaces exposed to sodium methoxide did not exhibit a change in the high level injection PL lifetime, and therefore this reagent produced an increase in the steady-state PL intensity by effecting a change in the surface Fermi-level position.

(3) XPS studies indicated that the aqueous $\mathrm{Na}_{2} \mathrm{~S}$ treatments acted as an etch for oxides and elemental arsenic, and yielded a small residual $A s_{x} S_{y}$ signal on the GaAs surface. However, exposure of GaAs surfaces to thiols did not yield detectable residual $\mathrm{As}_{x} \mathrm{~S}_{y}$ signals, indicating that the $A s_{x} S_{y}$ phase was not necessary for an increase in the GaAs PL signal. XPS data on GaAs samples exposed to thiols also showed that an enhancement in the PL signal could not be correlated with the amount of elemental arsenic initially present on the surface.

(4) Variation in the chemical identity of the passivating reagent from aqueous sulfides to nonaqueous thiols has yielded valuable information on the chemical nature of the important surface recombination sites. This chemical approach can potentially yield more relevant and predictive information than a surface stoichiometry analysis, because the magnitude of the PL effect was observed to decrease markedly when the overlayer was rinsed to expose the GaAs surface, and because the trap density may be sufficiently low that gross changes in surface stoichiometry may not accompany (or yield information regarding) the reactivity of the important surface recombination centers.

\section{ACKNOWLEDGMENTS}

We acknowledge the Department of Energy, Office of Basic Energy Sciences, for funding the research. S.R.L. also thanks the Department of Education for a graduate fellowship. We wish to thank Dr. E.-H. Cirlin of Hughes Research Laboratories, and Dr. M. Hecht and Dr. R. Vasquez of Jet Propulsion Laboratories for the use of XPS equipment and for numcrous helpful discussions. This paper is Contribution \#8420 from the Caltech Division of Chemistry and Chemical Engineering.

\footnotetext{
${ }^{1}$ (a) B. J. Skromme, C. J. Sandroff, E. Yablonovitch, and T. Gmitter, Appl. Phys. Lett. 51, 2022 (1987); (b) C. J. Sandroff, R. N. Nottenburg, and J. C. Bischoff, R. Bhat, Appl. Phys. Lett. 51, 33 (1987); (c) E. Yablonovitch, C. J. Sandroff, R. Bhat, and T. Gmitter, Appl. Phys. Lett. 51, 439 (1987).

${ }^{2}$ A. Heller, in Photoeffects at Semiconductor-Electrolyte Interfaces, edited by A. Nozik, ACS Symposium Series 146 (ACS, Washington, DC, 1981), pp. 57-77.

${ }^{3}$ (a) M. S. Carpenter, M. F. Melloch, and T. E. Dungan, Appl. Phys. Lett. 53, 66 (1988), (b) M. S. Carpenter, M. R. Melloch, M. S. Lundstrom, and S. P. Tobin, ibid. 52, 2157 (1988).

${ }^{4}$ (a) H. Hasegawa, T. Saitoh, S. Konishi, J. Ishii, and H. Ohno, Jpn. J. Appl. Phys. 27, L2177 (1988); (b) H. Hasegawa, H. Ishii, T. Sawada,
} 
T. Saitah, S. Kanishi, Y. Liu, and H. Ohno, J. Vac. Sci. Technol. B 6, 1184 (1988).

${ }^{5}$ (a) G. D. Pettit and J. M. Woodall, J. Vac. Sci. Technol. B 6, 1180 (1988); (b) C. W. Wilmsen, P. D. Kirchner, and J. W. Woodall, J. Appl. Phys. 64, 3287 (1988).

${ }^{6}$ C. J. Spindt, D. Liu, K. Miyano, P. L. Meissner, T. I. Chaing, T. Kendelewicz, I. Lindau, and W. E. Spicer, Appl. Phys. Lett. 55, 861 (1989).

${ }^{7}$ C. J. Spindt, R. S. Besser, R. Cao, K. Miyano, C. R. Helms, and W. E. Spicer, J. Vac. Sci. Technol. A 7, 2466 (1989).

${ }^{8}$ (a) R. S. Besser, C. R. Helms, Appl. Phys. Lett. 52, 1707 (1988); (b) D. Liu, T. Zhang, R. A. LaRue, J. S. Harris, and T. W. Sigmon, ibid. 53, 1059 (1988).

${ }^{9}$ T. Tiedje, P. C. Wong, K. A. R. Mitchell, W. Eberhardt, Z. Fu, and D. Sondericker, Solid State Commun. 70, 355 (1989).

${ }^{10}$ (a) B. A. Cowans, Z. Dardas, and W. N. Delgass, Appl. Phys. Lett. 54, 365 (1989), (b) M. S. Carpenter, M. R. Melloch, B. A. Cowans, Z. Dardas, and W. N. Delgass, J. Vac. Sci. Technol. B 7, 845 (1989).

${ }^{11} \mathrm{H}$. Hirayama, Y. Matsumato, H. Oigawa, and Y. Nannichi, Appl. Phys. Lett. 54, 2565 (1989).

${ }^{12}$ C. J. Sandroff, M. S. Hegde, L. A. Farrow, C. C. Chang, and J. P. Harbison, Appl. Phys. Lett. 54, 362 (1989).

${ }^{13}$ (a) K. M. Geib, J. Shin, and C. W. Wilmsen, J. Vac. Sci. Technol. B 8, 838 (1990); (b) J. Shin, K. M. Geib, C. W. Wilmsen, and Z. LillientalWeber, J. Vac. Sci. Technol. A 8, 1894 (1990); (c) T. Tiedje, K. M. Colbow, D. Rogers, Z. Fu, and W. Everhardt, J. Vac. Sci. Technol. B 7, 837 (1989).

${ }^{14}$ E. Yablonovitch, B. J. Skromme, R. Bhat, J. P. Harbison, and T. J. Gmitter, Appl. Phys. Lett. 54, 555 (1989).

${ }^{15}$ C. J. Spindt and W. E. Spicer, Appl. Phys. Lett. 55, 1653 (1989).

${ }^{16}$ A. Many, Y. Goldstein, and H. B. Grover, Semiconductor Surfaces (North-Holland, New York, 1965).

${ }^{17}$ M. Evenor, S. Gottesfeld, Z. Harzion, D. Hupert, and S. W. Feldberg, J. Phys. Chem. 88, 6213 (1984).

${ }^{18}$ S. W. Feldberg, M. Evenor, D. Huppert, and S. Gottesfeld, J. Electroanal. Chem. 185, 209 (1985).

${ }^{19}$ P. J. Grunthaner, R. P. Vasquez, and F. J. Grunthaner, J. Vac. Sci. Technol. 17, 1045 (1980).

${ }^{20}$ Material grown by organometallic vapor-phase epitaxy by Hugh MacMillan of Varian Associates, Palo Alto, CA.

${ }^{21}$ Material grown by molecular-beam epitaxy, and kindly supplied by $\mathrm{C}$. Sandroff of Bellcore, Red Bank, NJ.

${ }^{22}$ H. J. Stocker and D. E. Aspnes, Appl. Phys. Lett. 42, 85 (1983).

${ }^{23}$ B. J. Tufts, L. G. Casagrande, N. S. Lewis, and F. J. Grunthaner, Appl. Phys. Lett. 57, 2262 (1990).

${ }^{24}$ R. P. Vasquez, B. F. Lewis, and F. J. Grunthaner, J. Vac. Sci. Technol. B 1, 791 (1983).

${ }^{25}$ (a) M. Fukuda and K. Takahei, J. Appl. Phys. 57, 129 (1985); (b) D. Guidotti, E. Hasan, H. J. Hovel, and M. Albert, Appl. Phys. Lett. 50, 754 (1987); (c) T. Suzuki and M. Ogawa, ibid. 31, 473, 1977.

${ }^{26}$ D. E. Aspnes, S. M. Kelso, R. A. Logan, and R. Bhat, J. Appl. Phys. 60, 754 (1986).

${ }^{27}$ D. V. O'Conner and D. Phillips, Time-Correlated Single Photon Counting (Academic, London, 1984).

${ }^{28}$ (a) S. Canonica, J. Forrer, and U. P. Wild, Rev. Sci. Instrum. 56, 1754 (1985); (b) W. R. Ware, M. Pratinidhi, and R. K. Bauer, ibid. 54, 1148 (1983).

${ }^{29}$ (a) R. J. Nelson and R. G. Sobers, J. Appl. Phys. 49, 6103 (1978); (b) G. W. t'Hooft, Appl. Phys. Lett. 39, 389 (1981).
${ }^{30}$ J. A. Wurzbach and F. J. Grunthaner, J. Electrochem. Soc. 130, 691 (1983).

${ }^{31}$ J. H. Scofield, J. Electron. Spectrosc. Relat. Phenom. 8, 129 (1976).

${ }^{32}$ M. P. Seah and W. A. Dench, Surf. Interface Anal. 1, 2 (1979).

${ }^{33}$ E. W. Williams and R. A. Chapman, J. Appl. Phys. 38, 2547 (1967).

${ }^{34}$ S. Licht, F. Forouzan, and K. Longo, Anal.Chem. 62, 1356 (1990).

${ }^{35}$ (a) J. C. Bailor, H. J. Emeleus, R. Nyholu, and A. F. Trotman-Dickenson, Comprehensive Inorganic Chemistry Vol. I (Pergamon, Oxford, 1973), pp. 430-431; (b) Vol. II, p. 837.

${ }^{36} \mathrm{~A}$. Streitwieser and C. H. Heathcock, Introduction to Organic Chemistry (McMillan, New York, 1976), p. 1188.

${ }^{37}$ J. E. Huheey, Inorganic Chemistry, 3rd ed. (Harper and Row, New York, 1983), p. 313.

${ }^{38}$ (a) B. Smandek, G. Chmiel, and H. Gerischer, Ber. Bunsenges. Phys. Chem. 93, 1094 (1989); (b) G. J. Meyer, G. C. Lisensky, and A. B. Ellis, J. Am. Chem. Soc. 110, 4914 (1988).

${ }^{39}$ Full details of the modeling program used in our laboratory will be provided elsewhere: G. N. Ryba and N. S. Lewis (to be published).

${ }^{40}$ R. J. Nelson and R. G. Sobers, Appl. Phys. Lett. 32, 761 (1978).

${ }^{41}$ The spectra for etch $\mathrm{C}$ were taken with a VG nonmonochromatic $\mathrm{Al} K \alpha$ $x$-ray source on a modified VG HB50, ESCA III system.

${ }^{42}$ M. Pourbaix, Atlas of Electrochemical Equilibria in Aqueous Solutions (Pergamon, New York, 1966).

${ }^{43}$ The sample was oxidized and the lowest binding energy peak was taken to be $\mathrm{As}_{2} \mathrm{~S}_{3}$. This value matches well with that found in M. K. Bahl, R. O. Woodall, R. L. Watson, and K. J. Irgolic, J. Chem. Phys. 64, 1210 (1976).

${ }^{44}$ C. D. Wagner, W. M. Riggs, L. E. Davis, J. F. Moulder, and G. E. Muilenberg, Handbook of X-ray Photoelectron Spectroscopy (PerkinElmer, Eden Prairie, MN, 1979).

${ }^{45}$ C. P. Srivastanva, D. F. Van de Vondel, and G. P. Van Der Kelen, Inorg. Chim. Acta 23, L29 (1977).

${ }^{46}$ A. Wieckowski, in Modern Aspects of Electrochemistry, edited by R. E. White, J. O'M. Bockris, and B. E. Conway (Plenum, New York, 1990), pp. 65-119.

${ }^{47}$ T. J. Dunnhauser, M. O'Neil, K. Johnasson, D. Whitten, and G. McLendon, J. Phys. Chem. 90, 6074 (1986).

${ }^{48}$ (a) C. J. Murphy and A. B. Ellis, J. Phys. Chem. 94, 3082 (1990); (b) G. J. Meyer, L. K. Leung, J. C. Yu. G. C. Lisensky, and A. B. Ellis, J. Am. Chem. Soc. 111, 5146 (1989).

${ }^{49}$ J. C. Bailor, H. J. Emeleus, R. Nyholu, and A. F. Trotman-Dickenson, Comprehensive Inorganic Chemistry Vol. I (Pergamon, Oxford, 1973), p. 1238.

${ }^{50}$ B. J. Tufts, I. L. Abrahams, C. E. Caley, S. R. Lunt, G. M. Miskelly, M. J. Sailor, P. G. Santangelo, N. S. Lewis, A. L. Roe, and K. O. Hodgson, J. Am. Chem. Soc. 112, 5123 (1990).

${ }^{\text {S1 }}$ (a) J. C. Bailor, H. J. Emeleus, R. Nyholu, and A. F. Trotman-Dickenson, Comprehensive Inorganic Chemistry Vol. II (Pergamon, Oxford, 1973), p. 919; (b) F. A. Cotton, and G. Wilkinson, Advanced Inorganic Chemistry, 4th ed. (Wiley, New York, 1980), p. 458.

${ }^{52}$ R. C. Weast and M. J. Astle, Eds., Handbook of Chemistry and Physics, 63rd ed. (CRC, Boca Raton, 1983).

${ }^{53}$ Y. J. Chabal, Surf. Sci. 168, 594 (1986).

${ }^{54}$ W. E. Spicer, Z. Liliental-Weber, E. Weber, N. Newman, T, Kendelewicz, R. Cao, C. McCants, P. Mahowald, K. Miyano, and I. Lindau, J. Vac. Sci. Technol. B 6, 1245 (1988). 